\title{
BNWL-260
}

5 -

\section{A PRECISION LONG COUNTER FOR MEASURING \\ FAST NEUTRON FLUX DENSITY}

RESEARCH and

DEVELOPMERT REPORT
J. De Pangher and L. L. Nichols

\section{June, 1966}




\section{LEGAL NOTICE}

This report was prepared as an account of Government sponsored work. Neither the United States, nor the Commission, nor any person acting on behalf of the Commission:

A. Makes any warranty or representation, expressed or implied, with respect to the accuracy, completeness, or usefulness of the information contained in this report, or that the use of any information, apparatus, method, or process disclosed in this report moy not infringe privately owned rights; or

B. Assumes any liabilities with respect to the use of, or for damages resulting from the use of any information, apparatus, method, or process disclosed in this report.

As used in the above, "person acting on behalf of the Commission" includes any employee or contractor of the Commission, or employee of such contractor, to the extent that such employee or contractor of the Commission, or employee of such contractor prepares, disseminates, or provides access to, any information pursuant to his employment or contract with the Commission, or his employment with such contractor.

\section{PACIFIC NORTHWEST LABORATORY}

RICHLAND, WASHINGTON

operated by

BATTELLE MEMORIAL INSTITUTE

for the

UNITED STATES ATOMIC ENERGY COMMISSION UNDER CONTRACT AT(45-1)-1830 
BNWL-260

$\mathrm{UC}-37$, Instruments

(TID-4500)

A PRECISION LONG COUNTER

FOR MEASURING FAST NEUTRON FLUX DENSITY*

By

J. De Panghert and L. L. Nichols $†$

Radiological Physics Section

Environmental and Radiological Sciences Department

June, 1966

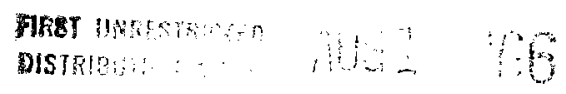

PACIFIC NORTHWEST LABOR ATORY

RICHLAND, WASHINGTON

* Work performed under the auspices of the U.S. Atomic Energy Commission at the Hanford Laboratories, General Electric Company and at the Battelle Northwest Laboratories in Richland, Washington.

†Present address, Lockheed Missiles and Space Company

†Participated in this work after August, 1962. 
Printed in USA. Price \$3.00. Available from the Clearinghouse for Federal Scientific and Technical Information

National Bureau of Standards

U. S. Department of Commerce Springfield, Virginia 


\section{ABSTR ACT}

A reproducible version of the Hanson-McKibben long counter was built and a comprehensive experimental investigation of its characteristics was made. The counter is made carefully from polyethylene and strengthened with aluminum instead of being paraffin strengthened with steel. It is called a precision long counter (PLC) because models built from a standard set of drawings have closely reproducible properties. Data are given to show how a PLC can be calibrated to within $1 \%$ for measuring neutron flux densities from radioactive sources. This calibration is obtained with a small calibrated PuBe neutron source inserted inside the PLC. The standard counter, $\mathrm{H}-1$, is located at Battelle-Northwest in Richland, Washington and the standard small source, $\mathbf{M}-1045$, is located at Mound Laboratory in Miamisburg, Ohio. One counter, H-3, was selected as a "roving" counter, was calibrated against $\mathrm{H}-1$, and was sent to the Mound Laboratory and to the Argonne National Laboratory to calibrate the two counters, ML-1 and ANL-1. The problem of using a PLC with accelerator neutrons is discussed and a solution offered. 


\section{TABLE OF CONTENTS}

Introduction . . . . . . . . . . . . . . . . . . . . . . . . 6

Description of the PLC . . . . . . . . . . . . . . . . . . . 7

Apparatus . . . . . . . . . . . . . . . . . . . . . . . . . 9

PLC BF $\mathrm{BF}_{3}$ Tubes . . . . . . . . . . . . . . . . . . . . . . 13

Comparison of PLC Responses for Different Polyethylene

Cores and Thermal Neutron Shields . . . . . . . . . . . . . 19

Properties of Radioactive Neutron Sources . . . . . . . . . . 21

Inverse Square and Shadow Shield Measurements . . . . . . . . 28

Energy Response of a PLC Relative to LC No. 2 . . . . . . . . 32

Reproducibility of PLC Response-Relative Measurements . . 34

Reproducibility of PLC Response-Absolute Measurements . $\quad 37$

Derivation of the $\mathrm{BF}_{3}$ Tube Sensitivity . . . . . . . . . . . . 45

Measurement of the Effect of Finite Counter Size . . . . . . . 48

Relative Response of a PLC in Different Kinds of Scattering

Geometry . . . . . . . . . . . . . . . . . . . . . 49

Use of the PLC with Accelerator Produced Neutrons . . . . . . 51

Reproducibility Checks on PLC's . . . . . . . . . . . . . . 56

Acknowledgments . . . . . . . . . . . . . . . . . . . . . 57

References . . . . . . . . . . . . . . . . . . . . . . 58

Appendix A . . . . . . . . . . . . . . . . . . . . . . . . 60

Appendix B . . . . . . . . . . . . . . . . . . . . . . . . 61 
LIST OF FIGURES

Figure

Number

1

2

3

4

5

6

7

8

9

10

11

12

13
Title

Page

9

12

14

16

18

19

30

32

McKibben Long Counter

34

$\theta_{1}=\theta_{2}=75^{\circ}$ with Accelerator Neutrons and

Neutrons from Radioactive Sources

Results of the Determination of $\alpha(\mathrm{H}-1)$ from Data

Taken with Four Different PLC's, with $\mathrm{BF}_{3}$

Tubes Having Different Wall Materials and

Isotopic Gas Composition, and with Two Different

Neutron Sources

42

43

to Different Radioactive Neutron Sources 
LIST OF FIGURE (Cont.)

Figure

Number

14

15

16

\section{Title}

Plots of $u_{1} / u_{2}, \theta_{1}$, and $\theta_{2}$ as Functions of the Neutron Energy for NBS-1 Irradiated with Neutrons from the $\mathrm{D}(\mathrm{d}, \mathrm{n}) \mathrm{He}^{3}$

Monoenergetic Neutrons Available for Five Commonly Used Neutron Producing Reactions

Graphs Showing How the Neutron Energy Can Be Varied by Using a $4.4 \mathrm{MeV}$ Accelerator at 1.0, 2. 0, 3.0, 3.7, and 4.0 MeV Bombarding Energy

\section{LIST OF TABLES}

Table Number

I

II

III

IV

V

VI

VII

VIII

IX

$\mathrm{X}$

XI

XII
Title

Results of Resolution Checks on the Brass $\mathrm{BF}_{3}$ Tube and on the Copper $\mathrm{BF}_{3}$ Tube

Results of the Counting-Rate Checks on the Brass $\mathrm{BF}_{3}$ Tube and on the Copper $\mathrm{BF}_{3}$ Tube

Comparison of Different Cores in Counter $\mathrm{H}-3$ with Accelerator Neutrons

Comparison of Different Thermal Neutron Shields in Counter $\mathrm{H}-3$ with Accelerator Neutrons

Constants of the Neutron Sources

Inverse Square Data for Run 52

Comparison of the Sensitivities of $\mathrm{H}-1$ and NBS-1 for Different Neutron Energies

Comparison of the Sensitivities of $\mathrm{H}-1$ and $\mathrm{H}-2$ for Different Neutron Energies

Comparision of the Sensitivities of Eight PLC's

Constants of the PLC for Different Radioactive Neutron Sources

Values of the Average Relative Efficiency of a PLC for Different Radioactive Neutron Source 



\section{A PRECISION LONG COUNTER}

\section{FOR MEASURING FAST NEUTRON FLUX DENSITY}

\section{$\underline{\text { INTRODUCTION }}$}

This report describes the design and testing of a reproducible counter ${ }^{(1)}$ which will overcome the reproducibility limitation of the HansonMcKibben counter. The main objective of this report is to discuss how reproducibility measurements are made and how calibration can be obtained for a precision long counter with radioactive neutron sources. The problem of measuring accelerator neutron sources is also discussed and a solution proposed.

This reproducible counter called the Precision Long Counter (PLC) is believed to have the characteristics required of a standard because a number of PLC's have been made from the design and shown to be reproducible to better than $1 \%$ and because its calibration can be obtained with a small neutron source. The source is permanently mounted in a source holder rod which accurately locates it within the PLC during the calibration.

In 1947 Hanson and McKibben developed the long counter ${ }^{(2)}$ at Los Alamos for measuring fast neutron flux densities. Since that time many copies of this neutron detector have been made. Probably, it is the most widely used of all neutron detectors. When calibrated against a radioactive neutron source for measuring flux density, the Hanson-McKibben counter has been used to calibrate other neutron detectors over the $25 \mathrm{keV}$ to $14 \mathrm{MeV}$ energy range. However, in spite of the importance of this detector, essentially only two efforts $(3,4)$ have been made to determine the variation of its sensitivity with changing neutron energy.

The Hanson-McKibben counter is made by pouring paraffin into the various compartments of a lightweight cylindrical container of welded steel. A proportional counter tube is commonly employed in the central axial hole to detect the fast neutrons which have been thermalized in the surrounding hydrogeneous medium. The counter tube has a $10 \frac{3}{8} \mathrm{in}$. sensitive length, a $\frac{1}{2}$ in. $\mathrm{OD}$, and is filled with enriched $\mathrm{BF}_{3}$ gas $\left(96 \% \mathrm{~B}^{10}\right.$ and $\left.4 \% \mathrm{~B}^{11}\right)$. 
BNWL-260

The neutron source whose flux density is to be measured is usually located on the axis of the counter about $100 \mathrm{~cm}$ from the front face.

Reduction of its response to room-scattered neutrons is achieved by filling one of the outer compartments of the metal container with boric anhydride $\left(\mathrm{B}_{2} \mathrm{O}_{3}\right)$ powder. This compartment, a $\frac{1}{2}$ in. thick cylindrical shell, separates the central paraffin core from the massive external paraffin shell. A series of eight holes, drilled in the core parallel to its axis, improved the response of the counter to neutron energies below $1 \mathrm{MeV}$. These holes are $1 \mathrm{in}$. in diameter, $3 \frac{1}{2} \mathrm{in}$. deep, and lie on a $3 \frac{1}{2} \mathrm{in}$. diameter circle.

In spite of its large size and weight (length and diameter about 16 in., weight about $100 \mathrm{lb}$ ), the long counter has been used extensively because of its high sensitivity for neutron detection, its uniform energy response, and its excellent discrimination against gamma radiation. Measurements made with radioactive neutron sources have disclosed the fact that the long counter acts like a point detector. ${ }^{(3)}$ The position of this point in the counter is energy dependent; the point or effective center moves deeper into the counter as the neutron energy increases.

The need for the long counter continues to be great because no satisfactory substitute has been found for it in measuring neutron radiation strongly contaminated with gamma radiation, two characteristic examples of which are the radiations from $\mathrm{RaBe}$ and $\mathrm{SbBe}$ sources. However, the Hanson-McKibben design does not yield a reproducible counter, a fact which can be most easily demonstrated with low energy neutrons. ${ }^{(5)}$ Thus, the results of an effort to calibrate one of these counters in one laboratory are not easily comparable to the results obtained with another counter in another laboratory.

DESCRI PTION OF THE PLC

The Model III PLC resulted after two earlier models were built and tested. Except for the thermal neutron shield, consisting of an aluminum can filled with $\mathrm{B}_{2} \mathrm{O}_{3}$ powder, Model I was built entirely out of polyethylene. It was unsuccessful as a reproducible standard because the unsupported polyethylene parts exhibited plastic flow under the force of gravity. 
Model II was successful in overcoming this weakness, but some of the brass parts in it had to be replaced with aluminum parts to obtain reproducible responses with an internal PuBe source. The brass parts involved were the brass liners for the brass $\mathrm{BF}_{3}$ tube and the brass source holder rod. These parts were obtained from the counters-H-1, H-2, and NBS-1-and tested one at a time inside H-1. A maximum variation of the count rate of about $3 \%$ was obtained in $H-1$. When new parts made from aluminum alloy were used instead of brass parts in the tests with $\mathrm{H}-1$, the maximum variation of the counting rate in the $\mathrm{BF}_{3}$ tube was less than $0.1 \%$. The counting rate in $\mathrm{H}-1$ with the aluminum parts was about $25 \%$ higher than when it contained the brass parts. This result is an added advantage since an increased count rate was desirable.

The next step made in processing Model III was to replace the aluminum part of the source holder by brass to avoid the difficulty of trying to slide aluminum against like metal. Finally, since comparison tests made on Model iI with calibrated radioactive neutron sources showed that the energy response for an annular-cut central core was as good as the response for an eight hole core, the simpler arrangement with the annular-cut core was employed in Model III. (The same amount of material was removed in making the two types of cores.)

Figure 1 shows a sketch of the Model III PLC. Machine drawings of it and the $\mathrm{BF}_{3}$ tube are available.* The dimensions of the polyethylene parts are approximately the same as the dimensions of the paraffin parts in the Hanson-McKibben counter. The main changes in the new design are:

- A large diameter $\mathrm{BF}_{3}$ tube

- A machineable thermal neutron shield made out of low molecular weight polyethylene impregnated with $5.00 \%$ boron**:

* Machine drawings of the Model III PLC are available from the Cooper-Trent Blueprint and Microfilm Corporation, 2701 Wilson Boulevard, Arlington, Virginia. These are copies of the Hanford drawings, H-4-39122, H-4-39153, $\mathrm{H}-4-39205$, and $\mathrm{H}-4-39206$ (CAPE 756). Two brass $\mathrm{BF}_{3}$ assemblies are shown in the drawing H-4-39122; Assembly No. 1 pertains to the Type $\mathrm{B} \mathrm{BF}_{3}$ tube used in the precision long counter. For specifications regarding a copper $\mathrm{BF}_{3}$ tube seen Appendix $\mathrm{A}$ of this report and for corrections to the PLC drawings see Appendix B.

**Made by Allied Resinous Products, Inc., P.O. Box 620, Conneaut, Ohio. 
- A retractable PuBe neutron source (1 $\left.\mathrm{g} \mathrm{Pu}^{239}\right)$ for internal calibration

- The use of aluminum alloy for the confinement of the polyethylene

- A larger cadmium shield on the front of the counter

- A rear cadmium shield instead of a rear $\mathrm{B}_{2} \mathrm{O}_{3}$ shield

- The use of low molecular weight polyethylene instead of paraffin

- An annular region instead of eight holes cut out of the central core.

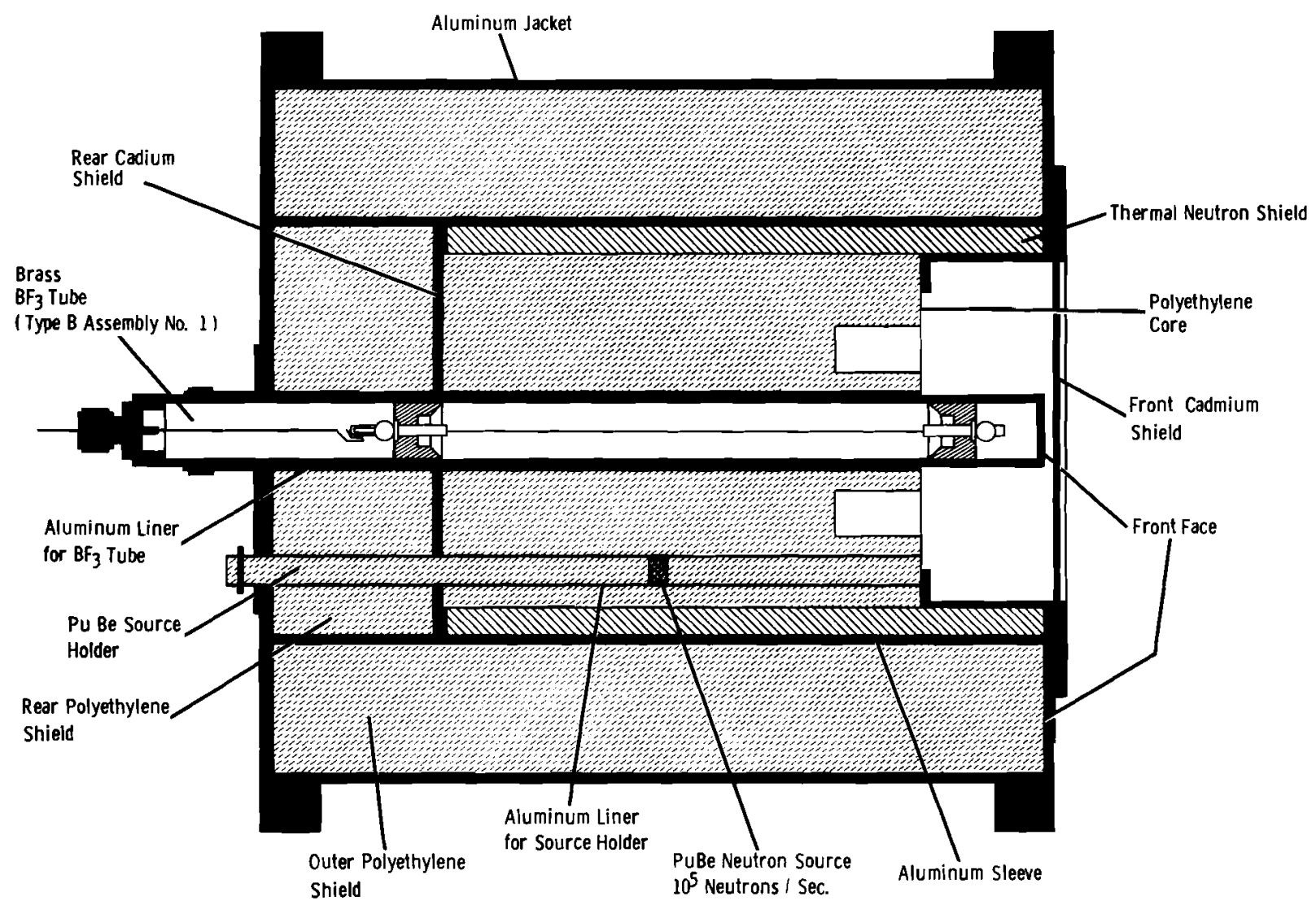

FIGURE 1. Sketch of PLC Showing $\mathrm{BF}_{3}$ Tube and Internal Neutron Source APPARATUS

Six PLC's were studied at Hanford: H-1, H-2, H-3, H-4, NBS-1, and $\mathrm{L}-1$. Counter $\mathrm{H}-1$ and $\mathrm{H}-3$ were made at Hanford, $\mathrm{H}-2$ and $\mathrm{H}-4$ were 
made by commercial vendors, NBS- 1 was made at the National Bureau of Standards, and L-1 was made by a commercial vendor for the Lawrence Radiation Laboratory in Livermore. The weight of a PLC is $150 \mathrm{lb}$.

A Hanson-McKibben type long counter, LC No. $2^{(5)}$, was made out of aluminum sheet instead of the steel sheet prescribed in the Los Alamos design. This counter weighs about $100 \mathrm{lb}$.

Extra polyethylene cores* and thermal neutron shields* (polyethylene impregnated with boron) were obtained to check on the reproducibility of counter $\mathrm{H}-3$ containing these parts. Usually the effect of room-scattered neutrons on the counting rates of the PLC's was obtained by making inverse square measurements; however, a shadow shield, which was made out of the same kind of material used for the thermal neutron shields, also served to determine this effect.

The PLC's were positioned by means of one of the following devices:

1. An instrument carrier ${ }^{(6)}$ which established a plane polar coordinate system $(r, \theta)$ with the neutron source at the origin;

2. An aluminum platform which could be bolted to the floor at a fixed position; or

3. An adjustable aluminum stand on wheels.

The above equipment was used in the low-scattering room which contains Hanford's positive ion Van de Graaff accelerator. This room contains an $8 \mathrm{ft}$ deep pit covered with a light weight aluminum grating floor. The pit covers an area 20 by $21 \mathrm{ft}$ in the center of a 28 by $29 \mathrm{ft}$ room. The ceiling is about $20 \mathrm{ft}$ high. Two of the walls are plasterboard; the other two contain considerable concrete. Most of the measurements were made 42 in. above the grating floor with the source of neutrons near the center of the room.

Of the three positioning devices listed, the instrument carrier is the most versatile and offers the lowest scattering arrangement. The PLC was suspended from it by wires, and it could be either manually or automatically controlled to follow a desired sequence of radial or angular settings.

*Procured from the Allied Resinous Products, Inc., Whitney and Clark Streets, Conneaut, Ohio. 
A steel source holder stand designed to give high visibility of the neutron sources was provided so that cylindrical sources could be held with their axes either horizontal or vertical. The stand was designed for manual or automatic measurements of the assymetry of the neutron emission rates from the sources.

The servo controls for the instrument carrier and the automated source holder stand consist of two precision potentiometers on each of the three systems: the radial system, the angular system, and the source holder rotational system. Three of these potentiometers (200 ohms) are in the radiation area, the other three are in the accelerator control room. Manual control is achieved by adjusting a potentiometer in the control room and then the servo system drives the positioner until the corresponding potentiometer linked to the mechanical drive in the radiation area is balanced. For automatic control a potentiometer in the control room is replaced by a chain of resistors, and a stepping switch is connected across them. The accuracy of positioning in the radial, the angular, and the source holder rotational systems is $\pm 0.3 \mathrm{~mm}, \pm 0.1^{\circ}$, and $\pm 0.1^{\circ}$, respectively.

Optical equipment was used to align the PLC axis along the desired directions. Pairs of removable cross hairs were provided for the PLC's to aid in the alignment. Three, $\frac{1}{8} \mathrm{in}$. collimator openings spaced about $1 \mathrm{in}$. apart limited wandering of the beam at the target, and thus minimized errors in the location of the accelerator neutron source. Dummy sources having fine scribed lines on them were used to carefully set the source holders in the desired position for containing the real sources.

Two systems of automatic counting equipment were used at various times in the PLC program to amplify, discriminate, and count pulses in the $\mathrm{BF}_{3}$ tubes or other radiation detectors. Each system contained two amplifiers, two stable high voltage supplies, two electronic counters, one dual preset counter, and a digital recorder. Usually the dual preset counter* counted pulses from a $60 \mathrm{cycle} / \mathrm{sec}$ mercury relay pulser. The dual feature of this counter permitted a count of duration, $t_{2}$, after a time delay, $t_{1}$, had

*Model 7446 Dual Preset Counter, Beckman/Berkeley Division, Richmond, California. 
taken place following the initiation of the start of the cycle. For example, the delay $t_{1}$ was adjusted to give adequate time for positioning of the instrument carrier in making inverse square measurements.

A voltage-to-frequency converter* was used as a beam-current integrator $^{(7)}$ with the quantity of charge determined by the two settings in the dual preset counter. A number of electronic counters could be gated simultaneously by the dual preset counter to give simultaneous measurement of the integrated current at the accelerator target and of the counts produced in the various radiation detectors measuring neutrons from the target.

Commercial versions of a brass $\mathrm{BF}_{3}$ tube, having a diameter of 1.5 in. and designed at Hanford for the PLC's, were made mostly by one vendor* and used throughout the work reported here. Figure 2 shows a

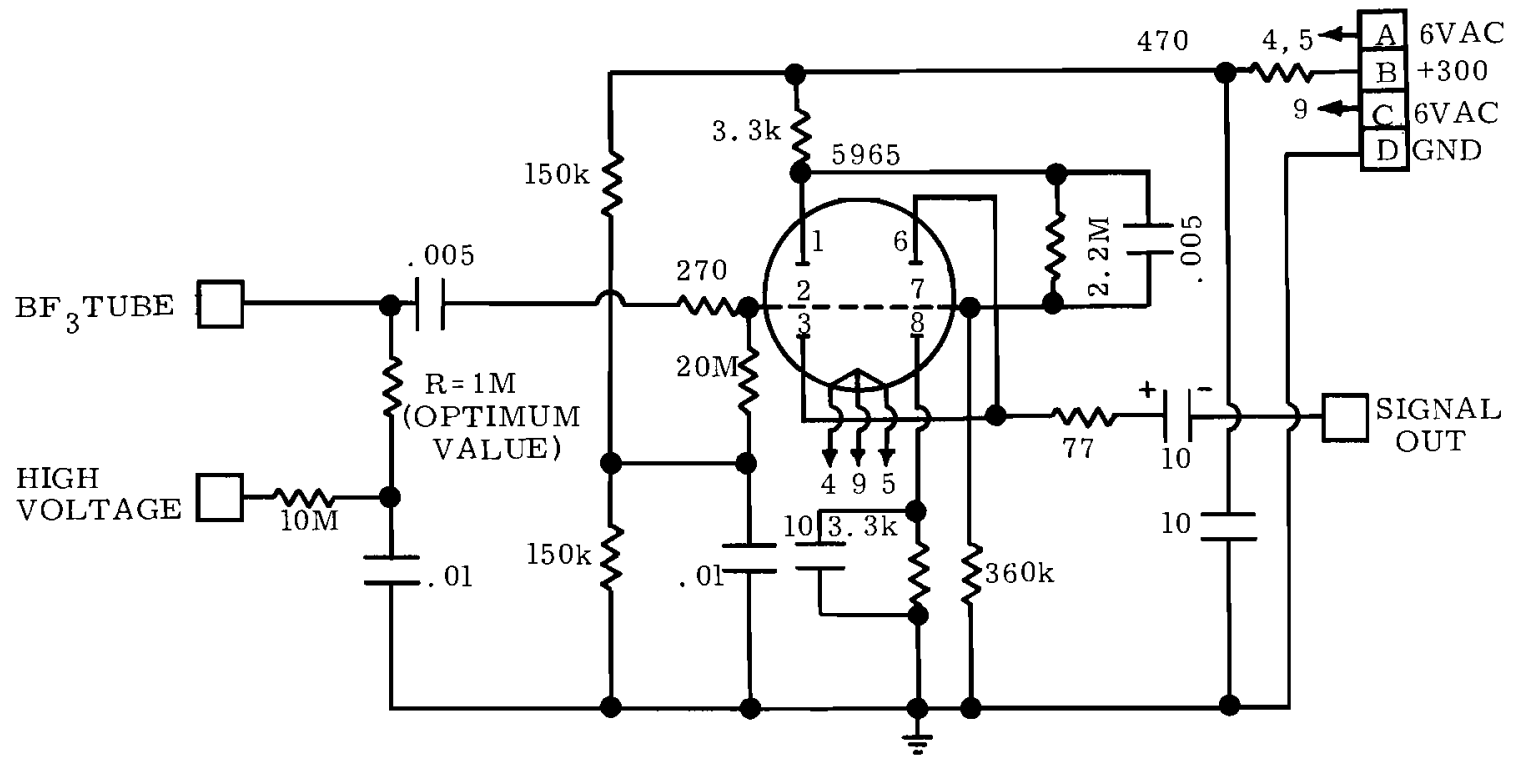

FIGURE 2. Schematic of White Cathode Follower Circuit to Which the $\mathrm{BF}_{3}$ Tube is Coupled Directly to Avoid Capacitance of a Connecting Cable

schematic drawing of the white cathode follower preamplifier used with the tube in such tests and in all PLC measurements. The $\mathrm{BF}_{3}$ tubes are

* Model 2210 Voltage-to-frequency Converter, Dymec, A Division of Hewlett Packard Co., 395 Page Mill Road, Palo Alto, California. **N. Wood Counter Laboratory, 1525 E. 53rd Street, Chicago Illinois. 
connected directly to the amplifier to avoid cable capacitance. Pulse distortion results if the signal resistor, $\mathbf{R}_{2}$ is reduced significantly below $1 \mathrm{M} \Omega$.

The studies with monoenergetic neutrons were done with neutrons from a $2 \mathrm{MeV}$ positive ion Van de Graaff accelerator. The following targets were employed:

- LiF on tantalum backings for Lijp, neutrons

- TTi or TZr on platinum backings for Tip, n neutrons

- Carbon on platinum backings for C $\mathrm{d}, \mathrm{n}$ neutrons

- $\mathrm{D}_{2}$ in a flow-gas cell ${ }^{(9)}$ or $\mathrm{DT}^{\circ}$ or DZr on platinum backings for $\mathrm{D}(\mathrm{d}, \mathrm{n})$ neutrons

- TTi or TZr on platinum backings for $T$, $\mathrm{T}$, nj neutrons.

The studies with neutrons having wider energy spectra were done with the following radioactive neutron source $\mathrm{S}_{\text {. Thre }}$ Iarge PuBe sources: $\mathrm{M}-199$, M-590, and NBS-H; one large $\mathrm{PuF}_{4}$ scurce: $\mathrm{PuF}_{4}-2$; one $\mathrm{Ra}-\gamma-\mathrm{Be}$ source: NBS-II; one Ra-a-Be source: RaBe 68B; and one SbBe source: $\mathrm{SbBe}-4$ were all used as external sources with the PLC's. Three small PuBe sources: M-246 (or M-246' after recanning), M-710 for M-710 after recanning), and M-1045 were used as internal sources with the PLC's. The source M-199, containing about $80 \mathrm{~g}$ plutonium, showed a small leak when subjected to the recanning process and was $r \in$ placed wth the scur $\mathrm{M}=1220$ 。

$\underline{\text { PLC BF}}_{3} \underline{\text { TUBES }}$

$\mathrm{BF}_{3}$ tubes were selected because they have better than $15 \%$ resolution on the main peak in the pulse height distributicn. Figure 3 shows the pulse height distribution obtained with a 256 channel analyzer for a particuiar $\mathrm{BF}_{3}$ tube, G-14023: when exposed to the internai PuBe neutron scurce. Its good quality is demonstrated by the $7 \%$ resolution on the main peak (Peak 2) which is produced when the $\alpha^{-p a r t i c l e ~ f r o m ~ t h e ~} \mathrm{~B}^{10}(\mathrm{n}, \alpha) \mathrm{Li}^{7}$ reaction leaves the $\mathrm{Li}^{7}$ nucleus in its first $\in \mathrm{x} \approx$ ited state $(478 \mathrm{keV}$ above the ground state). The other peak (Peak 1 cocurs when the Li ${ }^{7}$ nucleus is left in the ground state (about $5 \%$ cf the time).

*Built from the Hanford design by $\mathrm{N}$. Wood Counter Laboratcry, $1525 \mathrm{E}$. 53rd Street, Chicago, Illinois. 


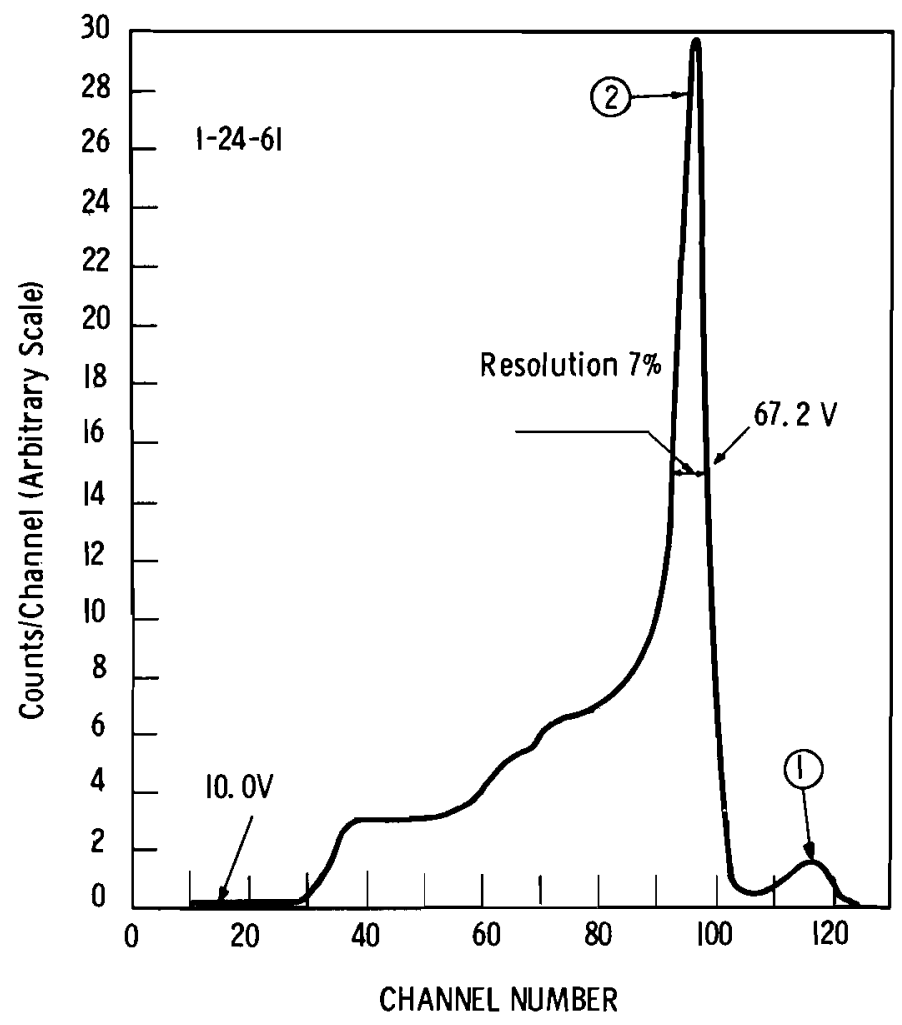

FIGURE 3. Pulse Height Distribution for the $\mathrm{BF}_{3}$ Tube, G-14023

The method now to be described for adjusting the gain of the counting system works very well for tubes having resolutions better than $25 \%$ but probably can be used with tubes having poorer resolutions. The criterion for setting up the counting system is to have

$$
\dot{A}(10.0)=(17.5 \pm 0.5) \dot{A}(67.2)
$$

where $\dot{A}(10,0)$ is the count rate with the amplifier discriminator set at $10.0 \mathrm{~V}$ and $\dot{A}(67.2)$ is the count rate with the amplifier discriminator set at $67.2 \mathrm{~V}$.

For tubes having resolutions similar to that of tube G-14023, an application of this criterion essentially means that two particular counting rates are to be adjusted relative to each other: one chosen at a flat place in the pulse height distribution and the other chosen at the most rapidly varying part of the distribution. When the criterion is applied to setting the system gain, the counting rate, $\dot{A}(10.0)$, for an internal PuBe source 
is defined as a characteristic rate. This rate is quite reproducible from day to day unless the $\mathrm{BF}_{3}$ tube has been in a radiation field long enough to experience adverse radiation effects. Characteristic rates are easily obtained for the $\mathrm{BF}_{3}$ tubes of the Hanford design by (1) setting the tube voltage at $1450 \mathrm{~V},(2)$ adjusting the amplifier gain to satisfy the criterion as closely as possible, and, then (3) making the final fine adjustment with the tube voltage.

Two kinds of radiation effects were discovered in the brass tubes: the first kind affected the counting rates, and the second kind affected the pulse height distributions. Both of these effects were easily observed for gamma radiation from the sources, RaBe68B containing $0.5 \mathrm{~g}$ of radium and NBS-II containing $\$ .0 \mathrm{~g}$ of radium, and for X-radiation from the $2 \mathrm{MeV}$ electron Van de Graaff accelerator at Hanford. Later, it was found that neutrons, also produced radiation effects which, with the relatively low intensities available, were more difficult to study. Exposure times with radium sources were made for times as long as 5 days to produce marked effects but an exposure time of only 20 min to $\mathrm{X}$-radiation from the electron accelerator was needed to produce even stronger effects.

These radiation effects somewhat limited the accuracy with which measurements could be made over long periods of time without repeated calibrations. This fact was disappointing because it had been hoped that the tube itself, free from leaks, might serve as a standard.

Two experiments were conducted to accentuate the two radiation effects described. The first experiment accentuated the resolution effect in a brass $\mathrm{BF}_{3}$ tube which was exposed to $200 \mathrm{R}$ of $\mathrm{X}$-radiation for $20 \mathrm{~min}$. During the exposure the center wire potential was held at a positive $1450 \mathrm{~V}$. Pulse height measurements were made on the $\mathrm{BF}_{3}$ tube before the exposure, immediately after the exposure, and a number of times thereafter until 7 days after the exposure. The results of the experiment are shown in Figure 4 in which the tube shows an initial resolution of $9 \%$, a distorted pulse height distribution following the exposure, a somewhat recovered distribution 1 day later, and a final resolution of $7 \%$ occurring 7 days later. 

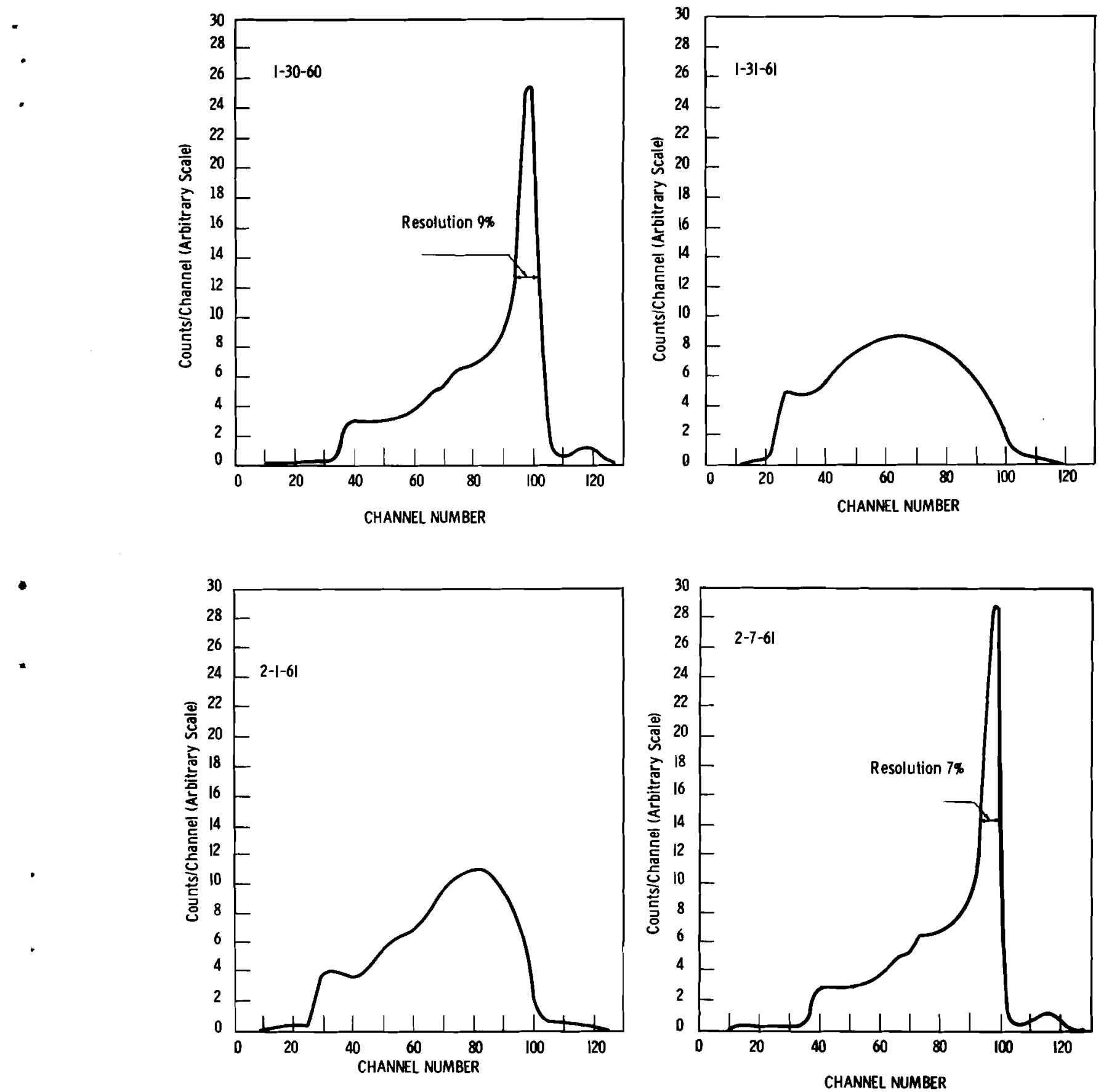

FIGURE 4. Effect on the Pulse Height Distribution Caused by Exposing the $\mathrm{BF}_{3}$ Tube, $\mathrm{G}-14023$, to $200 \mathrm{R}$ of $\mathrm{X}$-Radiation and the Subsequent Recovery of the Distribution 
The second experiment accentuated both the resolution and countrate effects and was the culmination of an effort to find a better $\mathrm{BF}_{3}$ tube than the brass tube. The search for a better tube first led to the testing of a pair of aluminum tubes* built according to the same design, but better results were not obtained. Finally a copper tube of a different design borrowed from the NBS was tested along with a brass tube by placing them in two PLC'S. $89 \mathrm{~cm}$ apart, and exposing them to the two sources, $M-590$ and $R$ aBe $68 \mathrm{~B}$, one at a time halfway between the PLC's over a period of 5 days.

The measured resolutions for the brass tube in the second experiment are given in Table I. They show three significant features: the source M-590 produces small but observable changes; the scurce RaBe68B, with its high gamma intensity in addition to its neutron intensity, produces pronounced changes; and the copper tube is superior to the brass tube in resisting the radiation.

TABLE I. Results of Resolution Checks on the Brass(a) $\mathrm{BF}_{3}$ Tube and on the Copper (b) $\mathrm{BF}_{3}$ Tube

\begin{tabular}{|c|c|c|c|}
\hline \multirow{2}{*}{$\begin{array}{l}\text { Exposure } \\
\text { Period, } \\
\text { min } \\
\end{array}$} & \multirow[b]{2}{*}{ Source(c) } & \multicolumn{2}{|c|}{$\begin{array}{l}\text { Resolutions at End } \\
\text { of Exposure Period } \\
\end{array}$} \\
\hline & & Brass Tube & Copper Tube \\
\hline 0 to 165 & $M-590$ & 10.4 & 7.5 \\
\hline 165 to 1543 & $M-590$ & 13.0 & 7.7 \\
\hline 1543 to 1612 & $68 \mathrm{~B}$ & 15.3 & 9.6 \\
\hline 1612 to 2852 & $68 \mathrm{~B}$ & 25.1 & 10.1 \\
\hline 2852 to 2912 & $M=590$ & 22.9 & 8.0 \\
\hline 2912 to 4638 & $M-590$ & 21.3 & 8.3 \\
\hline 4638 to 6157 & $M-590$ & 20.8 & 7.7 \\
\hline 6157 to 7130 & $M-590$ & 17.6 & 7.7 \\
\hline \multicolumn{4}{|c|}{$\begin{array}{l}\text { (a) Tube of the Hanford Laboratories' design built by N. Wood } \\
\text { Counter Laboratory, } 1525 \text { East } 53 \text { rd Street, Chicago, Illinois. }\end{array}$} \\
\hline \multicolumn{4}{|c|}{$\begin{array}{l}\text { (b) Tube of vendor's design built by } 20 t h \text { Century Electronics Ltd。, } \\
\text { King Henry's Drive, New Addington, Croydon, Surrey, England. }\end{array}$} \\
\hline \multicolumn{4}{|c|}{$\begin{array}{l}\text { (c) M-590 is PuBe source containing } 80 \mathrm{~g} \text { of plutonium while } 68 \mathrm{~B} \\
\text { is a } \mathrm{Ra}-\alpha-\mathrm{Be} \text { source containing } 0.5 \mathrm{~g} \text { of radium. }\end{array}$} \\
\hline
\end{tabular}

*Manufactured by Reuter Stokes Electronic Components, Inc. 2149 Hamilton Ave., Cleveland, Ohjo. 
The measured count-rate changes expressed in percent in the second experiment are given in Table II. The copper tube again show greater resistance to radiation than does the brass tube.

TABLE II. Results of the Counting-Rate Checks on the Brass $\mathrm{BF}_{3}$ Tube and on the Copper $\mathrm{BF}_{3}$ Tube

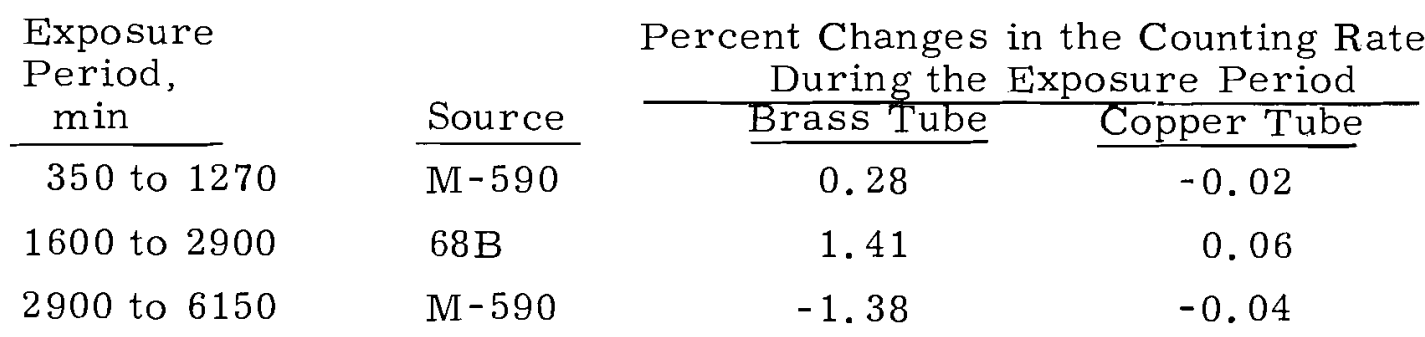

Three copper-walled $\mathrm{BF}_{3}$ tubes having the specification given in Appendix A were obtained too late to be used in the inverse square runs as standard $\mathrm{BF}_{3}$ tubes but were, nevertheless, evaluated regarding the count-rate radiation effect. The count-rate record of one of these tubes, UC-471, is shown in Figure 5 for a 2400 min exposure to source, RaBe $68 \mathrm{~B}$ and showed no count-rate radiation effect. This tube and the two other tubes obtained from the same vendor* yielded 7 to $9 \%$ resolution.

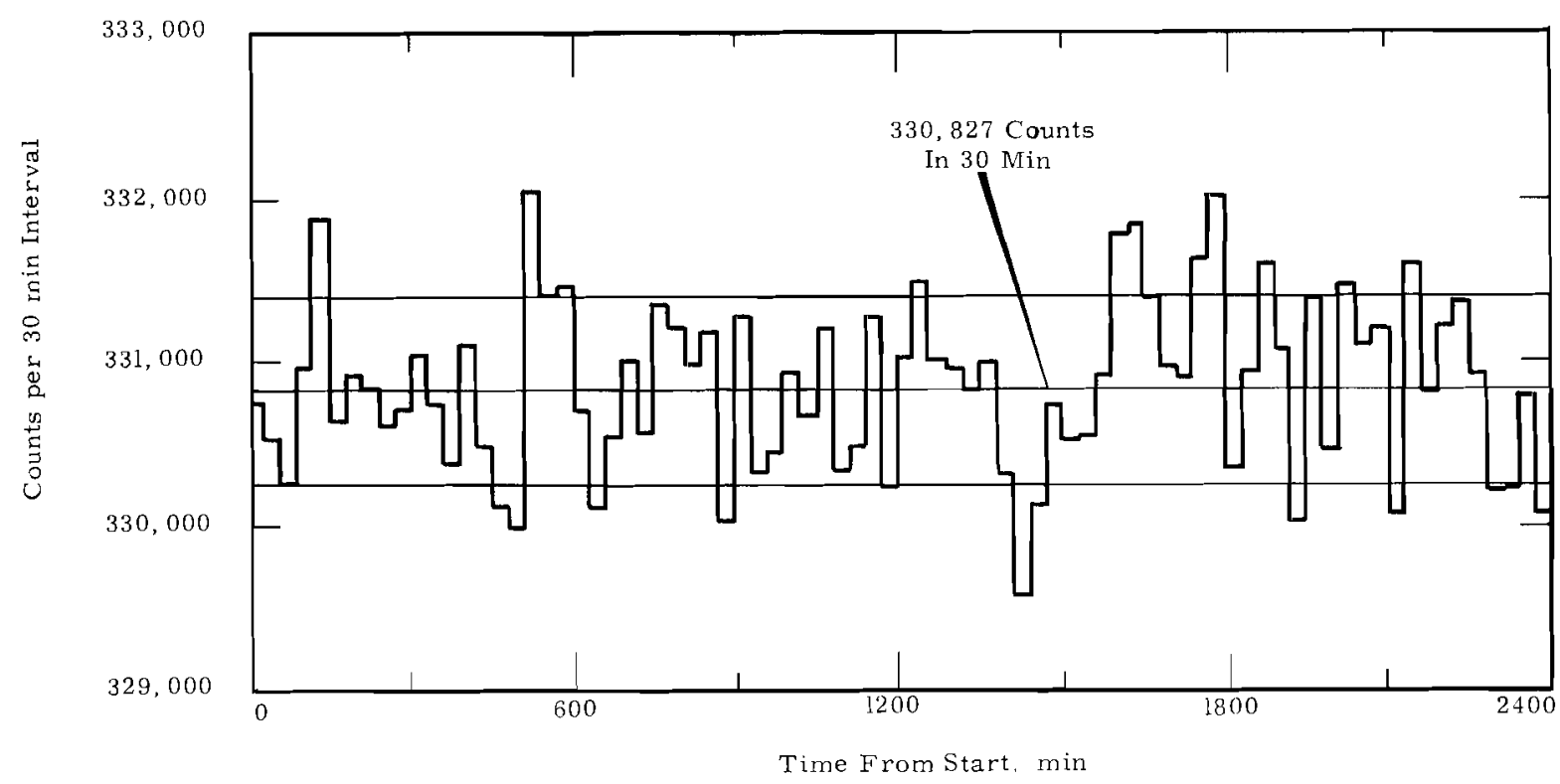

FIGURE 5. Count-Ratio Record for Oxygen-Free Copper $\mathrm{BF}_{3}$ Tube ShowingNo Radiation Effect When Exposed to $1 \mathrm{~g}$ RaBe Source

* Twentieth Century Electronics, Lts., King Henry's Drive, New Addington, Croyden, Surrey, England. 
The dead time in the $\mathrm{BF}_{3}$ tube and the associated counting equipment was measured by exposing the PLC to an accelerator neutron source of controllable intensity. This source, a thin beryllium layer evaporated on a platinum backing, was bombarded with deuterons from the accelerator and was monitored with the voltage-to-frequency converter used as a beam current integrator. The beam current was adjusted to give counting rates in the $\mathrm{BF}_{3}$ tube ranging from 80,000 to 780,000 counts/min. A linear plot of $[$ (counts/min)/ $/ \mathrm{A}]$ versus (counts/min) was analyzed to yield the dead time. The results of two separate measurements were 4.5 and $4.9 \mu \mathrm{sec}$. The average value, $4.7 \mathrm{\mu sec}$, was used to correct all count-rate data employed in this report.

\section{COMPARISON OF PLC RESPONSES FOR DIFFERENT POLYETHYLENE} CORE AND THERMAL NEUTRON SHIELDS

The arrangement for testing different polyethylene cores and thermal neutron shields in a PLC and also for comparing the PLC's against one another is illustrated in Figure 6. The monitor counter is a PLC suspended

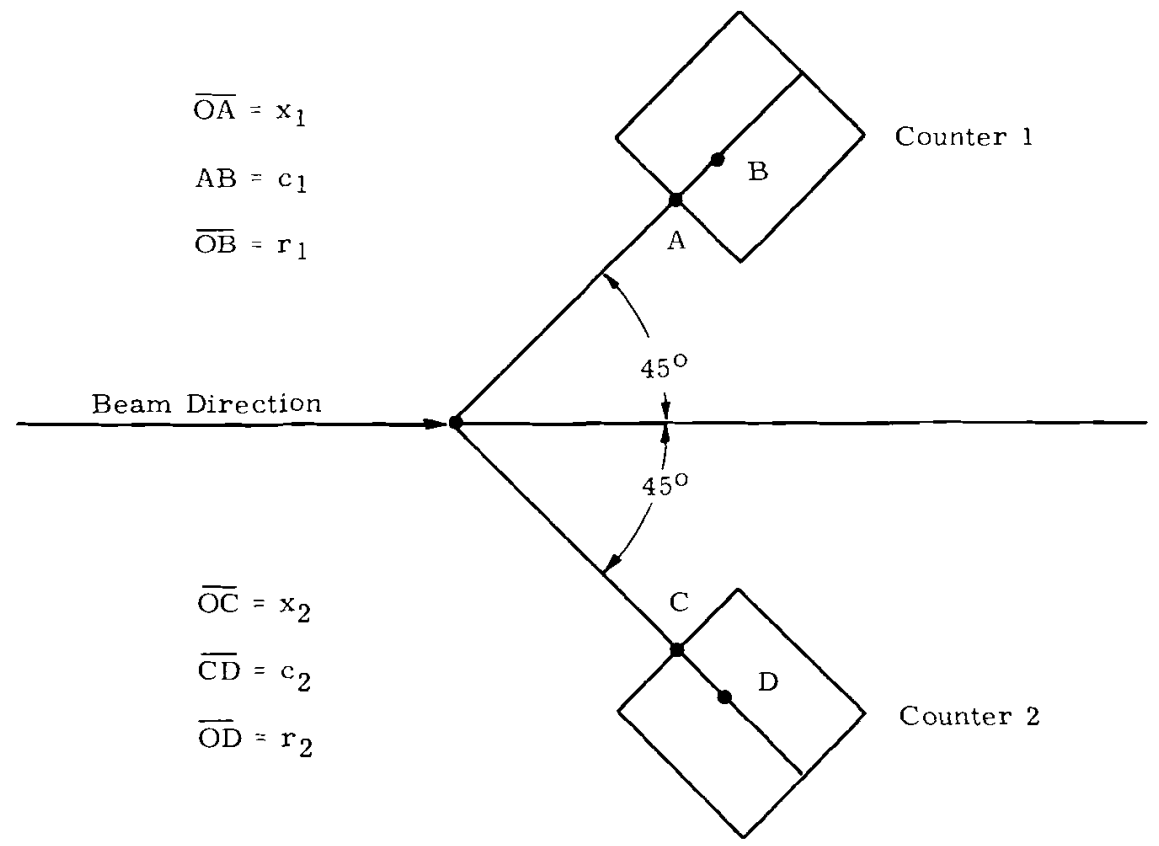

Accelerator Target at Point 0

FIGURE 6. Arrangement for Comparing PLC's with Accelerator Neutrons or Neutrons from Radioactive Sources 
from the instrument carrier at the angle, $\theta_{1}=45^{\circ}$, while the other PLC, H-3, is bolted securely to a fixed aluminum stand at the angle, $\theta_{2}=45^{\circ}$. The parts in $\mathrm{H}-3$ were exchanged with spare parts without loosening the bolts holding it to the stand. The source of neutrons was a TTi target bombarded by $1.5 \mathrm{MeV}$ protons.

Five polyethylene cores and four thermal shields were tested for reproducibility in the counter. The results of these tests are given in Tables III and IV and show that there is some lack of reproducibility in PLC cores. However, tests made with the thermal neutron shields showed these PLC parts to be very reproducible.

TABLE III. Comparison of Different Cores in Counter $\mathrm{H}-3$ with Accelerator Neutrons

\begin{tabular}{lcc} 
Core & Thermal Neutron Shield & Relative Sensitivity \\
\cline { 2 - 3 } $\mathrm{H}-3-1$ & $\mathrm{H}-3-1$ & 1.000 \\
$\mathrm{H}-3-3$ & $\mathrm{H}-3-1$ & 1.004 \\
$\mathrm{H}-3-4$ & $\mathrm{H}-3-1$ & 0.998 \\
$\mathrm{H}-3-5$ & $\mathrm{H}-3-1$ & 1.002 \\
$\mathrm{H}-3-7$ & $\mathrm{H}-3-1$ & 1.005 \\
Average & & $1.002 \pm 0.003$
\end{tabular}

TABLE IV. Comparison of Different Thermal Neutron Shields in Counter H-3 with Accelerator Neutrons

\begin{tabular}{lcc} 
Core & ThermalNeutron Shield & $\frac{\text { Relative Sen sitivity }}{\mathrm{H}-3-4}$ \\
\cline { 2 - 2 }$-3-3-1$ & $\mathrm{H}-3-2$ & 1.000 \\
$\mathrm{H}-3-4$ & $\mathrm{H}-3-3$ & 1.000 \\
$\mathrm{H}-3-4$ & $\mathrm{H}-3-4$ & 1.001 \\
$\mathrm{H}-3-4$ & & $1.000 \pm 0.001$ \\
Average & &
\end{tabular}




\section{PROPERTIES OF RADIOACTIVE NEUTRON SOURCES}

The source strength or emission rate, $Q(t)$, is time dependent for all sources used in the PLC work with the single exception of the $\mathrm{Ra}-\gamma-\mathrm{Be}$ source, NBS-II. Lack of knowledge of $Q(t)$ for the neutron sources containing plutonium was a major obstacle and would not have been overcome without the close cooperation of M。E. Anderson at Mound Laboratory。

The problem is that the isotopic composition in plutonium sources varies from source to source in a haphazard unpredictable manner. Plutoniun used for sources consists mostly of the $\mathrm{Pu}^{239}$ isotope with small amounts of the isotopes, $\mathrm{Pu}^{240}$ and $\mathrm{Pu}^{241}$, at the time of purification. The $\mathrm{Am}^{241}$ isotope builds up from the decay of the $\mathrm{Pu}^{241}$ isotope and causes the neutron emission rate to increase with increasing time until a maximum rate is reached 69. 5 yr later and then the neutron emission rate gradually decreases.

For the PuBe sources, the $\mathrm{PuF}_{4}$ source, and the $\mathrm{Ra}-\alpha-\mathrm{Be}$ source, the neutron emission rate changes according to

$$
Q(t)=Q(O)[1+A f(t)]
$$

where $Q(O)$ is the emission rate at the time of analysis, $A$ is a constant determined from an isotopic analysis, and $f(t)$ is a function defined in the expression below. For neutron sources containing plutonium, $A$ and $f(t)$ are given by

$$
\mathrm{A}=\frac{\frac{\mathrm{a}_{4}}{\mathrm{a}_{1}} \lambda_{4} \frac{\mathrm{N}_{3}}{\mathrm{~N}_{4}} \frac{\lambda_{3}}{\lambda_{4}-\lambda_{3}}}{\left(\lambda_{1}+\lambda_{2}\right) \frac{\mathrm{N}_{2}}{\mathrm{~N}_{1}}+\frac{\mathrm{a}_{4}}{\mathrm{a}_{1}} \frac{\mathrm{N}_{4}}{\mathrm{~N}_{1}}}
$$

and

$$
f(t)=e^{-\lambda} 3^{t}-e^{\lambda} 4^{t}
$$

(Somewhat loosely, the time of isotopic analysis of the source, $t=0$, is called the birthdate of the source.) The isotopic analysis gives the numbers $\mathrm{N}_{1}, \mathrm{~N}_{2}, \mathrm{~N}_{3}$, and $\mathrm{N}_{4}$ of $\mathrm{Pu}^{239}, \mathrm{Pu}^{240}, \mathrm{Pu}^{241}$, and $\mathrm{Am}^{241}$ atoms initially present in the plutonium. The values of decay constants $-\lambda_{1}, \lambda_{2}, \lambda_{3}$, and 
$\lambda_{4}$-are $9.016 \times 10^{-13}, 3.248 \times 10^{-13}, 1.689 \times 10^{-9}$, and $4.795 \times 10^{-11} \mathrm{sec}^{-1}$ and were calculated from the half-lives of the four isotopes. The quantity, $\mathrm{a}_{4} / \mathrm{a}_{1}$, is calculated from an application of the Runnals-Boucher ${ }^{(10)}$ formula and gives the dependence of the number of neutrons produced per million alpha particles on the alpha particle energy:

$$
a_{4} / a_{1}=\left(E_{4} / E_{1}\right)^{3.65}
$$

The numerical value is $a_{4} / a_{1}=1.23$ for the energies $E_{1}=5.22 \mathrm{MeV}$ $\left(\mathrm{Pu}^{239}\right)$ and $\mathrm{E}_{4}=5.56 \mathrm{MeV}\left(\mathrm{Am}^{241}\right)$. The initial growth rate, $\beta$ (expressed in $\%$ /yr) can be calculated by differentiating Equation (2) and by using the appropriate constants to give

$$
\beta=\left.\frac{100}{Q(O)} \frac{d Q}{d t}\right|_{t=0}=5.18 A .
$$

An example of the application of Equation (4) will now be given. The source, M-591, was measured calorimetrically by Anderson to yield $\mathrm{N}_{1} / \mathrm{N}=0.9473, \mathrm{~N}_{2} / \mathrm{N}=0.0481, \mathrm{~N}_{3} / \mathrm{N}=0.0046, \mathrm{~N}_{4} / \mathrm{N}_{1}=0.0000, \mathrm{~A}=-0.1763$, and $\beta=1.43 \% / y r$ where $\mathrm{N}=\mathrm{N}_{1}+\mathrm{N}_{2}+\mathrm{N}_{3}+\mathrm{N}_{4}$. For a Ra- $\alpha-$ Be source the emission rate is characterized $(11)$ by $A=-0.143$ and

$$
f(t)=e^{-t / 28.34}-1
$$

where $t$ is the time in years measured after the fabrication of the source.

Other PuBe sources studied calorimetrically by Anderson and used in the PLC work were M-199, M-591, and M-246. The latter source, mounted in its PLC source holder, was used to measure characteristic rates for all PLC's tested at Hanford until regulations of the U.S. Atomic Energy Commission required it to be recanned at Mound Laboratory along with a number of other PuBe sources. After it was recanned its designation was changed from M-246 to M-246'. Another source, M-710, which was shown to have the same neutron growth rate as $M-246$ was used as an interim standard while M-246 was being recanned. Eventually M-710 was recanned and now has the designation $M-710^{\prime}$. 
The grow th rate of two scurces, $\mathrm{PuF}_{4}-2$ and NBS-H were established from estimates made of the sources: isotopic ccmpositions.

The source, $M=1045$, is now regarded as the best choice as the secondary internal standard for pcssible inter a a ibrations of PLC's in various laboratories because. cf ali the small sources employed in PLC work, the growth rate of $\mathrm{M}-\mathrm{i} 045$ is best known. 52 Anderson has established its initial growth rate in two different ways. The first method employed by Anderson was to measure characteristic rates for $\mathrm{M}: 045$ with a particular $\mathrm{BF}_{3}$ tube in his PLC (ML-1) over an extended per:od of time. This method assumes a permanence of the $\mathrm{BF}_{3}$ tube sensitivity. Care was taken to avcid radiation effects.* The second method employed by Anderson was to compare characteristic rates with rates measured with an exterral PuBe source $(\mathrm{Pu}-3\rangle$ : this source had a very smail inital growth rate. This second method did not require the assumption of the permanene of $B F_{3}$ tube sensitivity.

Ancther source, M-1209, having the same isctopic composition as M-1045 and mounted in a PLC source holder, was measured by R.L.Brambiett (12) at the Lawrence Radiation Laboratcry. Anderson's result 12 of $1.95 \pm$ $0.04 \% / y r$ for M-1045 agreed quite ilosely with Bramblett's result of $1.83 \% / \mathrm{yr}$ for M-1209. Bramblett's method was the same as Arderson's first method but only two measurements of rharacteristic rates were taken in his PLC $(L-1)$ about 2 yr apart to yield his resuit.

$\mathrm{K}$. W. Geiger ${ }^{(13)}$ suggested that a $\mathrm{Pu}^{238} \mathrm{~B} \in$ source would have a predictable growth rate. For example, a sour e containing $81.94 \% \mathrm{Pu}^{238}$, $15.01 \% \mathrm{Pu}^{239}, 2.47 \% \mathrm{Pu}^{240}, 0.50 \% \mathrm{Pu}^{241}$, and $0.06 \% \mathrm{Pu}^{242}$ by an adaptation of Anderson s formula $13 \%$ yields $\beta=0.78 \%$, yr. Such a source was delivered to and tested at Hanford. How $v e r$, it was made from a pow dered mixture of $\mathrm{PuO}_{2}$ and berylizum instead of the durable PuBe 13 complex and thus, failed to yield good results as a reproducible neutron standard.

The assymetry ratio, $\varepsilon(\theta)$ for a cylindrisal radioactive neutron source is defined by the equation

$$
\varepsilon\left(\theta j=\frac{2}{I}[A(\theta)-a]\right.
$$

*Two different $B F_{3}$ tubes, $G-14023$ ard $G-13911$, both tainted by radiation effects caused by exposures to the sourees, RaBe68B and NBS, failed to yield good data regarding the growth rate for the Hanford source M-246. 
with

$$
I=\int_{0}^{\pi}[\AA(\theta)-a \sin \theta] d \theta
$$

where $\theta$ is the angle between the source axis and the source detector line, $\dot{A}(\theta)$ is the counting rate of the detector measuring the neutrons from the source, and $\underline{a}$ is the counting rate caused by room-scattered neutrons. The measurement is made by rotating a horizontal source about a vertical line through its center and the detector is held in a fixed position. The assymetry constant is the assymetry ratio evaluated at $\theta=90^{\circ}$; i.e., $\epsilon\left(90^{\circ}\right)$.

All measurements of $\epsilon\left(90^{\circ}\right)$ were made with the front faces of the PLC's about $88 \mathrm{~cm}$ from the source centers. The procedure for measuring a will be discussed later. One precaution must be taken as a result of the fact that $\AA\left(90^{\circ}\right)$ measured for a horizontal source is about $0.9^{(14)}$ higher than it is for a vertical source. The difference can be avoided by not mixing horizontal data with generally more abundant vertical data.

Two methods have been tried for evaluating $\underline{I}$ in Equation (9) and yield the same accuracy. The first method by Anderson uses Gauss' quadrature formula ${ }^{(15)}$ for seven selected data points in the interval, $0^{\circ} \leq \theta \leq$ $180^{\circ}$. The other method by ourselves uses Simpson's rule for 72 equally spaced data points. The simplicity of Anderson's method is evident in that it was developed for the purpose of determing $\epsilon\left(90^{\circ}\right)$ quickly for many sources. However, the use of automatic equipment in obtaining the 72 data points with the second method allowed the data for one source to be gathered in a single overnight exposure in the accelerator room.

The internal source was used by mounting it securely in its PLC source holder rod and inserting this arrangement in a PLC to measure a characteristic rate. When the PLC was used to measure neutron flux densities from external sources, this internal arrangement was removed from the PLC and left a vacant hole. There are two opposite ways in which the source holder rod can be locked in place, one of which was arbitrarily defined as the normal ( $n$ ) way and the other, then, became the reversed ( $r$ ) way. The handle end of the polyethylene rod was identified regarding the 
the normal way of using it by notching the top end of it and marking the bottom of the notch with the most permanent ink available.

The turnover constant $\mathrm{p}$, for a particular internal source is defined as the ratio of two characteristic rates: (1) $\AA(r)$ for the reversed way of inserting the source holder rod and (2) $\AA(n)$ for the normal way of inserting the source holder rod; i.e.

$$
\mathrm{p}=\dot{\mathrm{A}}(\mathrm{r}) / \dot{\mathrm{A}}(\mathrm{n}) \text {. }
$$

This turnover constant was used to check the mechanical stability of the internal source by measuring it from time to time during the course of the work.

The temperature dependence of the characteristic rate of a $\mathrm{BF}_{3}$ tube inside a PLC containing its internal neutron source was measured both at Hanford ( 14 to $24.5{ }^{\circ} \mathrm{C}$ for $\mathrm{H}-3$ ) and at the Mount Laboratory (ML-1) and yielded the same result, $0.035 \% /{ }^{\circ} \mathrm{C}$. The temperature dependence arises from the expansion (or contraction) of polyethylene with increasing (or decreasing) temperature.

Constants of Radioactive Neutron Sources

The constants of the neutron sources based on the primary external standards (NBS-I) and the secondary internal standard (M-1045) are shown in Table V. The significance of the entries made in the first three columns should be evident.

The fourth column gives values of $A$ for the sources-M-199, M-591, and $M-246-$ which are based on calorimeter data supplied by M. E. Anderson. The sources M-590 and M-591 were made from the same batch of plutonium and, presumably, are characterized by the same value of $\underline{A}$. An isotopic analysis supplied the data from which $\underline{A}$ was calculated for NBS-H. An estimate of the isotopic composition of the source, $\mathrm{PuF}_{4}-2$, yielded the value of $\mathrm{A}$ for that source. Measurements of the relative characteristic rates taken with sources $M-246$ and M-710 showed that the se sources have the same values of $A$, providing their birthdates were assumed to be identical. The source $\mathrm{M}-1045$ yielded $\mathrm{A}=-0.3978$ based on count-rate data supplied by Anderson. 


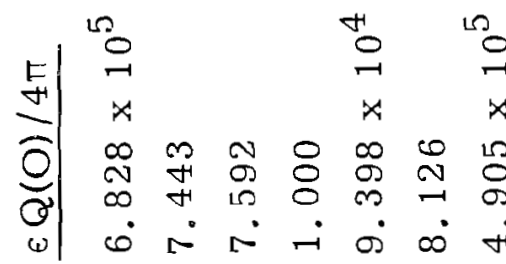

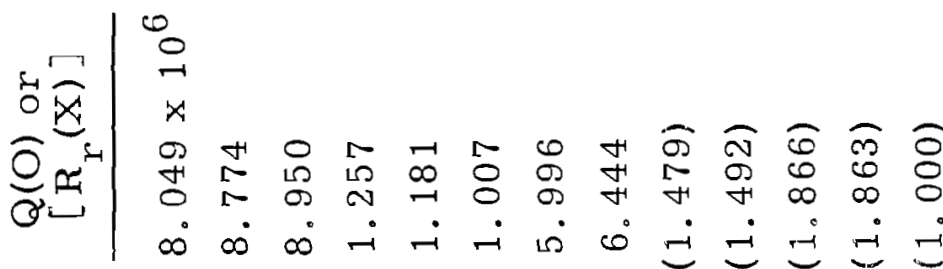

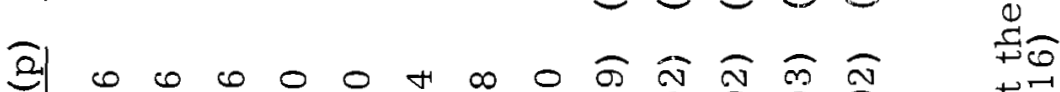

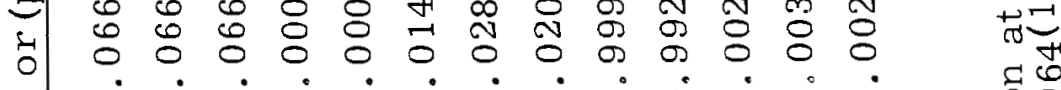

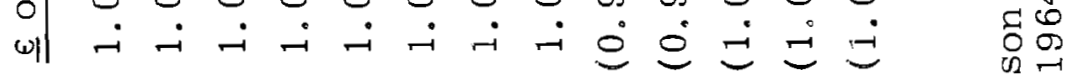

0
0
0
0
0

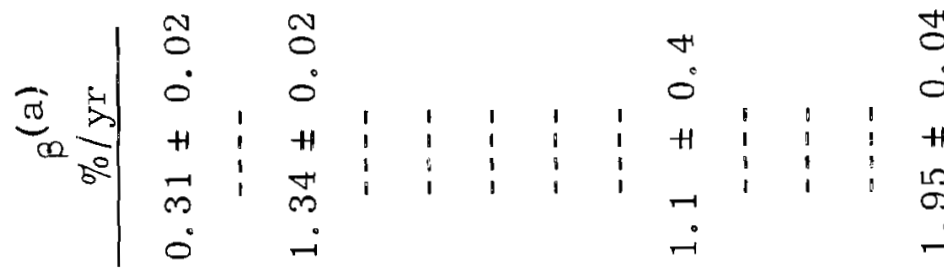

\&.

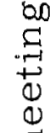

en

œ

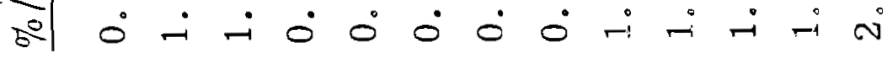

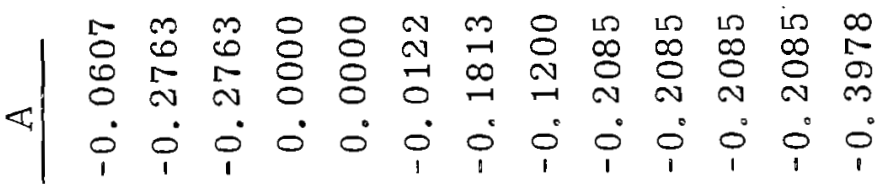

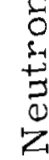

$\stackrel{0}{+\infty}$

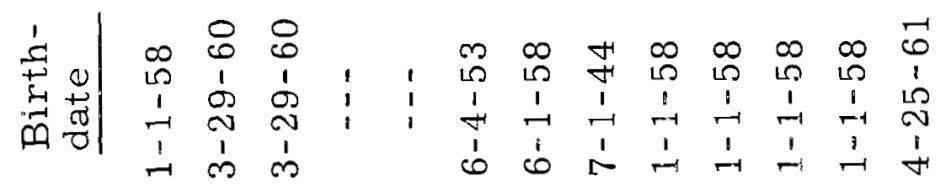

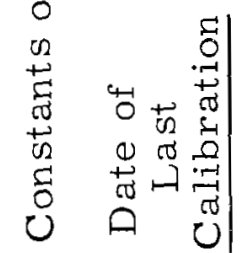

$$
00 \leftarrow \rightarrow-1
$$

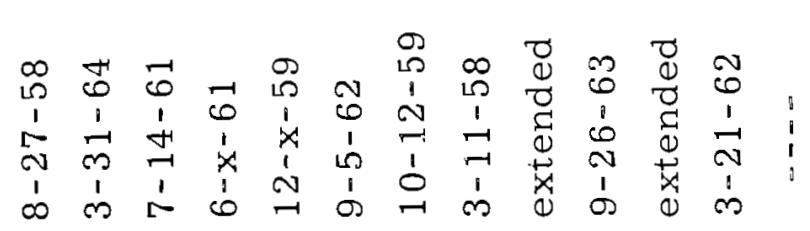

息|

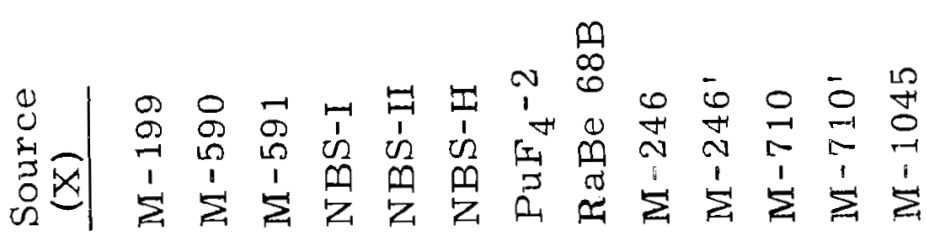


These values of $\underline{A}$ just described are the ones used in the PLC work and, by use of Equation (6), are converted into the values of $\beta$ given in the fifth column. For comparison purposes, the most recent values of $\beta$ determined by Anderson (12) are given in the sixth column. The differences in the corresponding values of $\beta$ are insignificant.

The assymetry constant, $\epsilon$, and the turnover ratio, p, which have been defined previously, are tabulated in the seventh column. For the sources M-199 and M-590, measurements of $\varepsilon$ taken at Mound Laboratory and at Hanford gave results agreeing within $0.3 \%$. For the source M-710', measurements of $\underline{p}$ made in the two laboratories gave results agreeing within $0.1 \%$. Other values of $\underline{\epsilon}$ and $\underline{p}$ given in the seventh column are expected to have accuracies corresponding to the examples given with the exception of $\epsilon$ for the $\mathrm{PuF}_{4}-2$ source because the powder content of this source was not tightly compacted at the time of its fabrication.

The emission rate, $Q(O)$, and the reduced ratio of characteristic rates, $R_{r}(X)$, (to be discussed later) are tabulated in the eighth column. The emission rate, $Q(t)$, was measured at the date of calibration for each source and then corrected back to its birthdate to yield Q O \% . The source NBS-I is used as the primary external standard; and, by means of the manganese sulfate bath technique, the sources M-199, M-591, NBS-II, NBS-H, and RaBe $68 \mathrm{~B}$ were calibrated against it at the National Bureau of Standards. The source M-590 was calibrated against the source M-199 at Hanford and, also, against the source M-591 at Mound Laboratory with PLC's. The source $\mathrm{PuF}_{4}{ }^{-2}$ was calibrated against the source NBS-II at Hanford with LC No. 2. The source M-1045 is used as the standard internal source and the sources, $M-246$ or $M-246^{\prime}$ and $M-710$ or $M-710^{\prime}$, were calibrated directly or indirectly against it at both Mound Laboratory and Hanford to yield the values of $R_{r}(X)$ tabulated inside the parentheses. The entries in the ninth or last column are values of the flux density at $1 \mathrm{~cm}$ from the side of each external source at the time, $t=0$. 


\section{IN VERSE SQUARE AND SHADOW SHIELD MEASUREMENTS}

The quantity $\underline{x}$ is defined as the perpendicular distance (in centimeters) between the center of the source and the plane containing the front face (see Figure 1) of the outer polyethylene shield and the front face of the $\mathrm{BF}_{3}$ tube in the PLC. Thus, the center of the front face of a properly constructed and positioned $\mathrm{BF}_{3}$ tube serves as a convenient reference point which becomes accessible when the front cadmium shield is removed. Inverse square measurements were made by measuring the counting rate $\dot{A}(x)$ as a function of the distance $x$ for values of $x$ uniformly distributed, over the interval, $42 \mathrm{~cm}<\mathrm{x}<209 \mathrm{~cm}$, with the number of positions ranging from 10 to 15 . The purpose of these measurements made in free air geometry was to measure the constants a, b, and c in the equation.

$$
A=a+\frac{b}{(x+c)^{2}}
$$

The counting times were adjusted to give essentially the same number of counts at each position. Eighty-five runs, each lasting from 8 to $64 \mathrm{hr}$, were made for different sources, tubes, and PLC's. The data were analyzed with an IBM 7090 computer program which is a Hanford adaptation of a generalized least squares program developed at Los Alamos. It minimized the sum, $\Sigma$, of the squares of the fractional deviations of the measured counting rates, correction was made on each counting rate for a dead-time loss. Table VI shows the inverse square data obtained in a typical run (Run 52) having 13 data points. The least squares analysis gave $a=287 \pm 7, b=(1150 \pm 4) \times 10^{5}, c=11.6 \pm 0.1$, and $\Sigma=2.70 \times 10^{-5}$ when fitted to Equation (11).

Anderson ${ }^{(19)}$ has fitted his inverse square data (14 points) obtained with PLC (ML-1) with the source M-591 to the equation

$$
\dot{A}=a(1-d x)+\frac{b}{(x+c)^{2}}
$$

Shadow shield measurements made for two different values of $\mathrm{x}$ were employed to set the value of $d$ at $1.033 \times 10^{-3}$. Least squares fitting of the data then led to $\mathrm{a}=1389 \pm 25, \mathrm{~b}=(1657 \pm 12) \times 10^{5}, \mathrm{c}=11.7 \pm 0.3$, and $\Sigma=6.1 \times 10^{-5}$. 
TABLE VI. Inverse Square Data for Run 52

\begin{tabular}{cc}
$\mathrm{x}, \mathrm{cm}$ & $\mathrm{A}$, Counts/min \\
\cline { 2 - 2 } 42.28 & 39948 \\
56.24 & 25290 \\
70.12 & 17522 \\
84.05 & 12848 \\
97.92 & 9905 \\
111.70 & 7837 \\
125.68 & 6381 \\
139.53 & 5323 \\
153.30 & 4518 \\
167.20 & 3894 \\
181.09 & 3378 \\
195.04 & 2975 \\
208.95 & 2650
\end{tabular}

The room used in this work has a concrete floor which is 20 by $27 \mathrm{ft}$, concrete walls, and a light weight ceiling which is $10 \mathrm{ft}$ high. The PLC was attached to an overhead trolley by a brass tube, 4 in. diameter by $0.065 \mathrm{in}$. thick wall and moved along a horizontal line $5 \mathrm{ft}$ above the floor. Measurement of the characteristic rate with the source M-1045 gave 30936 counts/min when corrected for the dead time loss. The scattering in Anderson's room must come mostly from the floor giving the result, $a / b=8.3 \times 10^{-6}$, compared with the result, $a / b=2.5 \times 10^{-6}$ obtained in the accelerator room at Hanford.

Two different accelerator neutron sources were tried in attempts to make inverse square runs with accelerator produced neutrons, $T(p, n)$ neutrons from a thin TZr target bombarded with $1.5 \mathrm{MeV}$ protons, and $\mathrm{C}(\mathrm{d}, \mathrm{n})$ neutrons from a thin carbon target bombarded with $1.5 \mathrm{MeV}$ deuterons. The counter, PLC ( $\mathrm{H}-3)$ was moved in 12 equal steps from $\mathrm{x}=50 \mathrm{~cm}$ to $\mathrm{x}=200 \mathrm{~cm}$ along straight lines making different angles $w i t h$ the incident beam direction. Two different monitors were tried: the fixed PLC (H-4) at $\theta=135^{\circ}$ as a neutron monitor and the voltage-to-frequency converter as a beam current integrator. The H-3 counts, the H-4 counts, and the 
integrated current were measured for each position of $\mathrm{H}-3$; and the counting times were selected to give equal counts in $\mathrm{H}-3$ at each position. In order to conserve accelerator time the beam current was gradually increased while $\mathrm{x}$ was being increased.

This experiment did not yield useful results when the data were analyzed because neither the beam current integrator or the PLC monitor were reproducible monitors of the neutron yield. The beam current integrator failed to give constant $\mathrm{H}-3$ or $\mathrm{H}-4$ counts for either target. It became evident that $\mathrm{H}-4$ failed as a monitor when $\mathrm{H}-3$ was moved closer than $80 \mathrm{~cm}$ from the target because of the scattering of neutrons from $\mathrm{H}-3$ into $\mathrm{H}-4$.

Figure 7 shows the arrangement for measuring the response of a PLC to room-scattered neutrons with a shadow shield. The shadow shield and PLC were both suspended from the instrument carrier so that the angle, $\theta$, could be varied. Another PLC placed at about $100 \mathrm{~cm}$ from the source and located at $\theta=220^{\circ}$ was used as a monitor. During the measurement the PLC was set with its front face at $190 \mathrm{~cm}$ from the source while the end of the shadow shield nearest the source was $8.7 \mathrm{~cm}$ from the source. Measurements were made with two radioactive neutron sources, $\mathrm{RaBe} 68 \mathrm{~B}$ and PuBe M-590, and with accelerator neutrons.

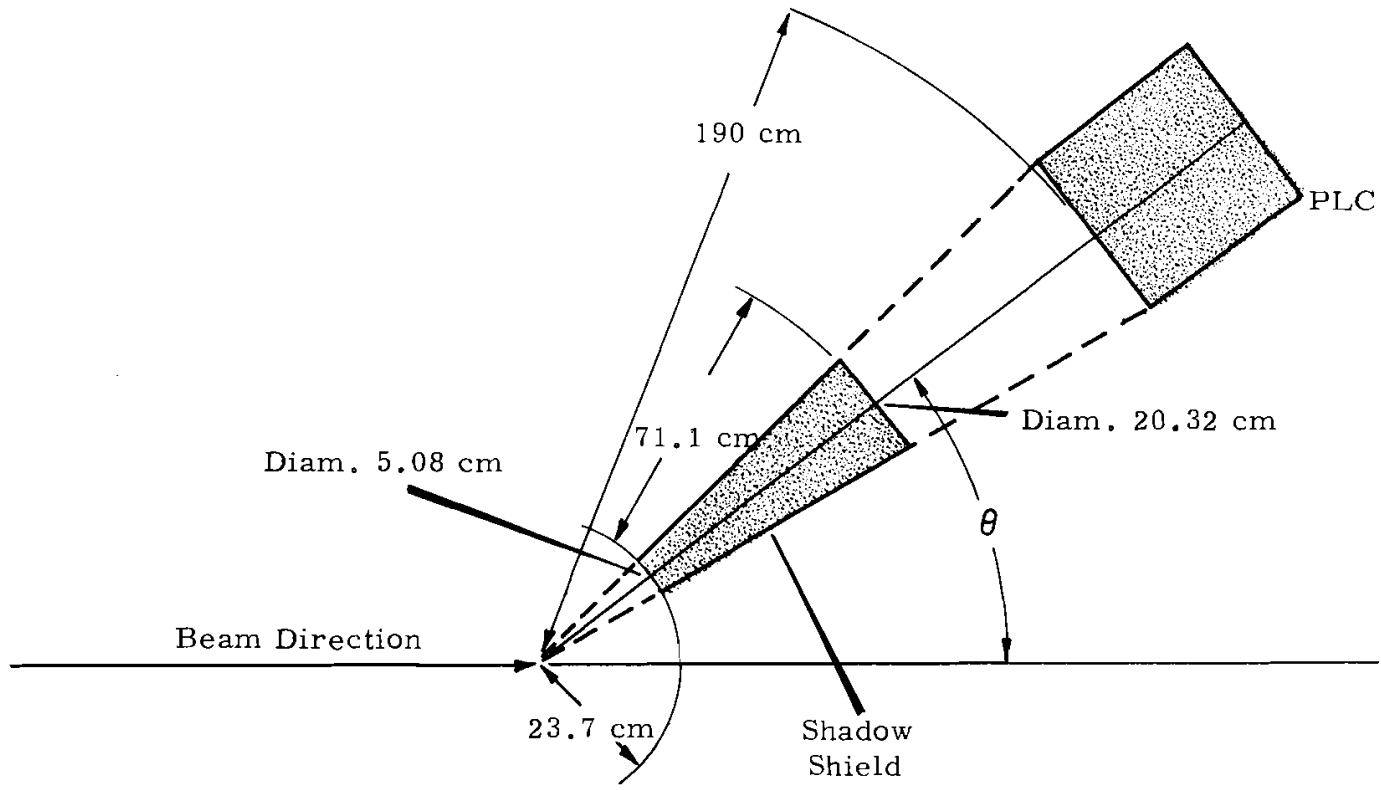

FIGURE 7. Arrangement for Measuring the Response of a PLC to RoomScattered Neutrons with the Aid of a Shadow Shield 
The results with radioactive neutron sources gave shielded PLC rates a' which are not angular dependent and are about $30 \%$ larger than the rates a obtained from the inverse square runs. In addition, measurements made with neutrons produced in a TZr target bombarded by $1.9 \mathrm{MeV}$ protons gave a constant ratio-(shielded PLC counts)/(monitor PLC counts)when the angle was varied.

The question is now raised about what would happen if only $\underline{b}$ and $\underline{c}$ were allowed to vary in the minimization of $\Sigma$ and $\underline{\text { a }}$ was set at $1.3 \times 283=370$ (using the data from Run 52). This method of analysis which starts with a fixed and $\underline{b}$ and $\underline{\mathrm{c}}$ variable gave $\underline{\mathrm{b}}=(1110 \pm 5) \times 10^{5}, \mathrm{c}=10.5 \pm 0.2$, and $\Sigma=4.02 \times 10^{-4}$. The first method of analysis, i.e., the one used in this paper, is preferred because it yields smaller deviations in $\underline{b}$ and $\underline{c}$ and gives a considerably smaller value of $\Sigma$.

Figure 8 shows data regarding $\underline{c}$ for Long Counter No. 2 (LC No. 2) used at Hanford and $\underline{c}$ for a long counter used at Harwell. These data fit the following equations:

$$
\mathrm{c}=10.1+1.1 \overline{\mathrm{E}}
$$

for LC No. 2 and

$$
\mathrm{c}=7.0+1.1 \overline{\mathrm{E}}
$$

for the Harwell counter. In plotting these data, use was made of the results of some studies made on the interpretation of spectra for several radioactive neutron sources with an instrument called the "double moderator." $(16,18)$ The most significant result of these studies was probably the fact that $\overline{\mathrm{E}}=3.6 \mathrm{MeV}$ for the $\mathrm{Ra}-\alpha-\mathrm{Be}$ neutron spectrum.

The $3.1 \mathrm{~cm}$ difference in the values of $\underline{\mathrm{c}}$ can be partly explained by the two different methods of analysis mentioned above. About $1.0 \mathrm{~cm}$ of the remaining difference is believed to come from the fact that the front face of LC No. 2 is warped. The remaining $1.0 \mathrm{~cm}$ difference has not been explained. 

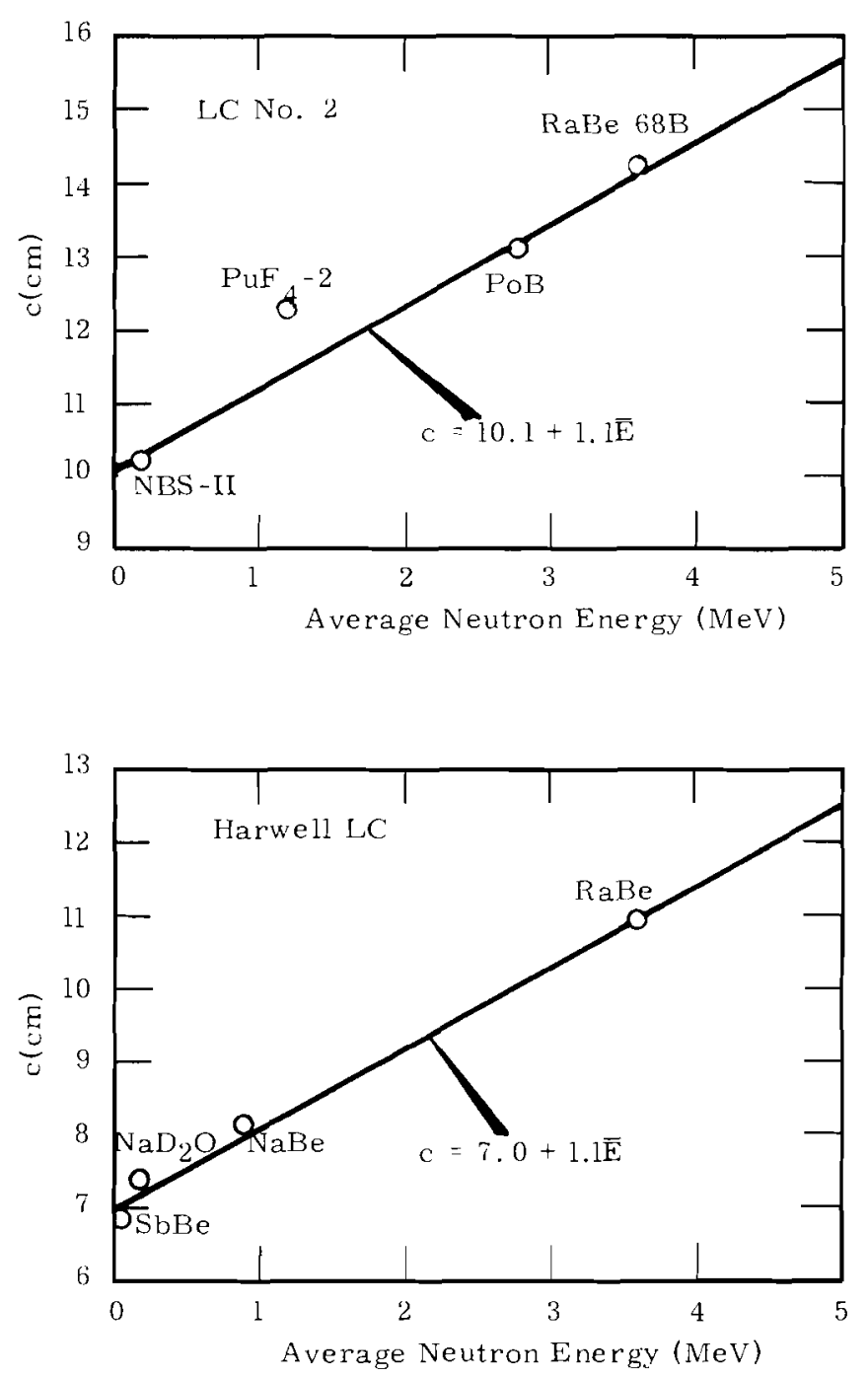

FIGURE 8. Variation of the Distance, c, from the Front Face to the Effective Center of LC No. 2 and the Harwell LC

\section{ENERGY RESPONSE OF A PLC RELATIVE TO LC NO. 2}

Figure 9 shows a composite curve ${ }^{(5,16)}$ which has been used for

LC No. 2 in calibrating radioactive neutron sources and accelerator neutron sources. This counter was built from the Hanson-McKibben design except that it contains aluminum instead of steel as the reinforcing material. The 
composite curve was plotted from data obtained at Harwell for one long counter ${ }^{(3)}$ and from data obtained at Los Alamos for another long counter. The relative efficiency, $\eta(E)$, is arbitrarily normalized to unity at the neutron energy, $\mathrm{E}=1.5 \mathrm{MeV}$. The average relative efficiencies for the radioactive neutron sources were calculated from the composite curve and from their neutron energy spectra.

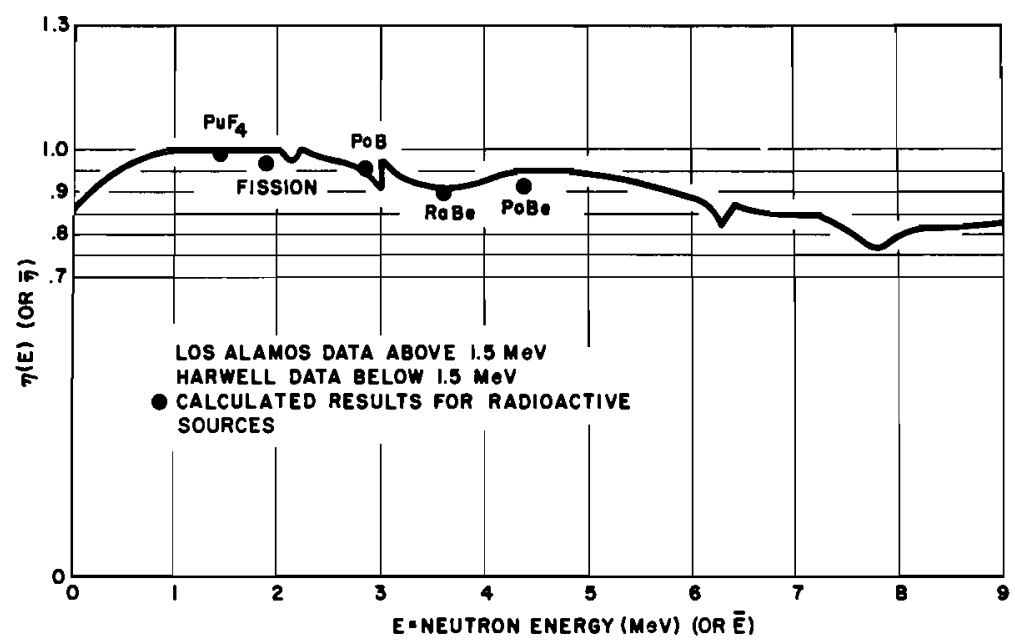

FIGURE 9. Relative Efficiency, $\eta(E)$, for the Hanson-McKibben Long Counter

Figure 6 which was used to describe an experiment to compare two PLC'S is appropriate for describing an experiment to compare one PLC with LC No. 2 which, presumably, has the energy response described in Figure 9. Two comparisons were made as a function of the energy of the neutrons coming from the accelerator target; one at $\theta_{1}=\theta_{2}=45^{\circ}$ and the other at $\theta_{1}=\theta_{2}=75^{\circ}$. One counter, LC No. 2, was located at $\mathrm{x}_{1}=85.9 \mathrm{~cm}$ while the other counter, NBS- 1 , was located at $\mathrm{x}_{2}=87.9 \mathrm{~cm}$. Additional measurements were made with neutrons from the sources $\mathrm{SbBe}-4, \mathrm{PuF}_{4}-2, \mathrm{RaBe} 68 \mathrm{~B}$, and PuBe M-199.

The condition, $99.5 \mathrm{~cm} \leq \mathrm{x}=\mathrm{c} \leq 100.0 \mathrm{~cm}$, was satisfied for the two counters PLC (NBS-1) and LC No. 2 duringthe measurement of $\xi=$ (NBS- 1 counts)/(LC No. 2 counts) as a function of $\mathrm{E}$ for monoenergetic accelerator neutrons and as a function of $\bar{E}$ for neutrons from radioactive sources. The measured values of $\xi(E)$ are shown plotted in Figure 10 and 
yield slightly different data trends for the angles $\theta_{1}=\theta_{2}=45^{\circ}$ and $\theta_{1}=\theta_{2}=75^{\circ}$. Differences in the two similar counters evidently occur when the se counters are placed in radiation fields not exhibiting symmetry around the counter axes and exhibiting greater nonuniformity than is present with radioactive neutron sources.

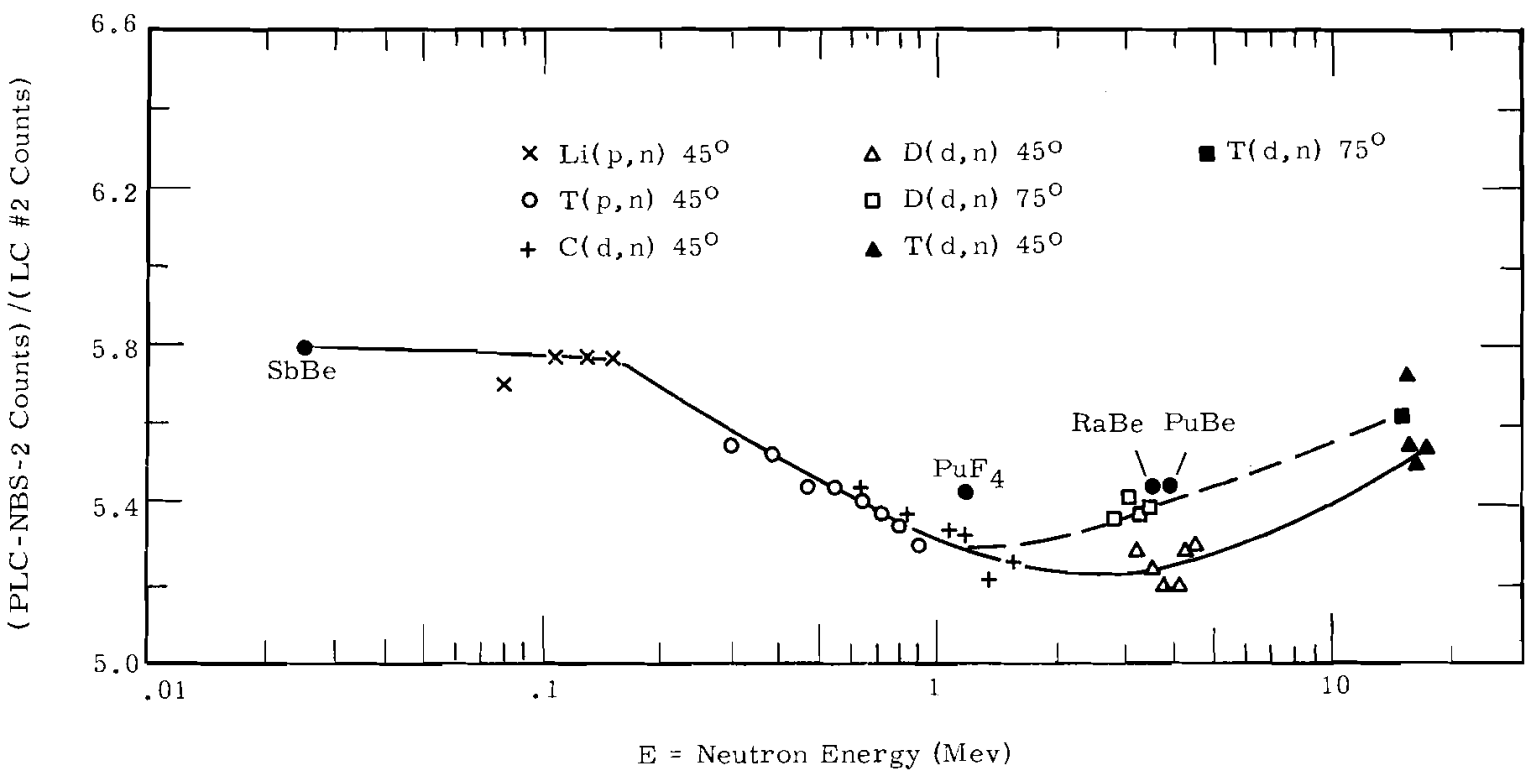

FIGURE 10. Energy Dependence of $\xi=$ (NBS-1 counts) $/($ LC No. 2 counts)

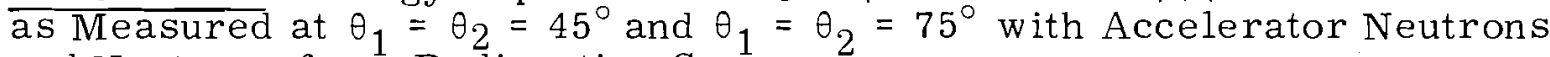
and Neutrons from Radioactive Sources

\section{REPRODUCIBILITY OF PLC RESPONSE-RELATIVE MEASUREMENTS}

In comparing the responses of a particular PLC, $\mathrm{Y}$, to the PLC regarded as standard, $\mathrm{H}-1$, two quantities were measured:

$r(Y)=\frac{\text { counts in tube inside } Y \text { exposed to internal source }}{\text { counts in same tube inside } H-1 \text { exposed to same internal source }}$

and

$s(y)=\frac{\text { counts in tube inside } Y \text { exposed to external source }}{\text { counts in same tube inside } \mathrm{H}-1 \text { exposed to same external source }}$.

The external source was either a radioactive neutron source or a monoenergetic source produced with the accelerator. A third quantity,

$$
w(y)=s(Y) / r(Y) \text {, }
$$


was actually used as the comparison index for the counter $\mathrm{Y}$ and would have a value of unity if the counters were truly identical.

The procedure for measuring $r(Y)$ is very simple and will not be discussed further. However, the procedure for measuring $s(Y)$ especially with the accelerator as a function of the neutron energy is more involved and will be discussed in some detail. When the accelerator was used as the neutron source the arrangementshown in Figure 6 was used for comparing counters and the angles of the two counters were set exactly at $\theta_{1}=\theta_{2}=45^{\circ}$. This adjustment was easy to make but because the counters were located on adjustable stands on wheels it was harder to match source-detector distances closer than $\left|\mathrm{x}_{1}-\mathrm{x}_{2}\right|<0.6 \mathrm{~cm}$ and corrections had to be made for the different distances. These corrections were made with the aid of Equation 11.

An accuracy of $\pm 0.1 \%$ can be achieved by a careful procedure of interchanging $\mathrm{BF}_{3}$ tubes and counters. To illustrate this procedure, consider the way in which the counter NBS- 1 was compared with the counter H-1 for neutron energies of $0.152,0.331,0.690,1.341,4.29$, and 16.92 MeV. First, NBS-1, containing tube G-14023 was placed at $x_{1}=87.63 \mathrm{~cm}$ and $\theta_{1}=45^{\circ}$ while $\mathrm{H}-1$, containing tube $\mathrm{G}-14121$, was placed at $\mathrm{x}_{2}=87.48$ $\mathrm{cm}$ and $\theta_{2}=45^{\circ}$. The ratio of the counts was measured. Second, the tubes were exchanged and the ratio of the counts was measured. Third, NBS-1, containing tube G-14121, was placed at $x_{2}=88.03 \mathrm{~cm}$ and $\theta_{2}=45^{\circ}$ while $\mathrm{H}-1$, containing tube G-14023, was placed at $\mathrm{x}_{1}=87.78 \mathrm{~cm}$ and $\theta_{1}=45^{\circ}$. The ratio of the counts was measured. Fourth, the tubes were exchanged and the ratio of the counts was measured. Two values of $\mathrm{s}(\mathrm{NBS}-1)$ resulting from these measurements were averaged to yield the final value of $s(\mathrm{NBS}-1)$ for each neutron energy. Only three neutron energies-0.331, 0.690, and 16. $92 \mathrm{MeV}$-were selected for different determinations of $\mathrm{s}(\mathrm{H}-2)$ because the values of s(NBS-1) had shown no energy dependence. About $80 \mathrm{hr}$ of accelerator time were required to supply the data leading to the final values of $\mathrm{s}(\mathrm{NBS}-1)$ and $\mathrm{s}(\mathrm{H}-2)$.

A simpler and less time-consuming comparison procedure consisted in aiming two PLC's toward a radioactive neutron source located halfway 
between them and making counts on the source. Two internal sources, two external sources, and two $\mathrm{BF}_{3}$ tubes were exchanged relative to the two PLC's to yield adequate comparison data in two days. This procedure was used in one recent comparison of $\mathrm{H}-2$ against $\mathrm{H}-1$ and in a second recent comparison of $\mathrm{H}-3$ against $\mathrm{H}-1$.

Table VII lists values of $\mathrm{s}(\mathrm{NBS}-1)$ and $w(\mathrm{NBS}-1)$ which were measured for NBS-1 as a function of neutron energy. No energy dependence was observed. Table VIII lists similar data obtained for $\mathrm{H}-2$ and also does not show energy dependence. However, it is clear that the response of the NBS-1 agrees more closely to $\mathrm{H}-1$ than does the response of $\mathrm{H}-2$. Table IX lists values of the quantities, $r(Y), s(Y)$, and $w(Y)$, which were obtained for eight different PLC's. The quantities $s(Y)$ and $w(Y)$ were measured with accelerator neutrons for $\mathrm{H}-1, \mathrm{NBS}-1, \mathrm{H}-2, \mathrm{H}-3, \mathrm{H}-4$, and L-1 at Hanford; with PuBe neutrons for the roving $\mathrm{H}-3$ and the $\mathrm{ML}-1$ at Mound Laboratory; and with PuBe neutrons for the roving $\mathrm{H}-3$ and the ANL-1 at the Argonne National Laboratory. Finally, after the work with the roving $\mathrm{H}-3$ was completed and it was returned to Hanford, it and $\mathrm{H}-2$ were compared with $\mathrm{H}-1$. The stability of $\mathrm{H}-2$ relative to the $\mathrm{H}-1$ over a 31 month period is evident; however, the $0.6 \%$ increase in the response of the roving counter $\mathrm{H}-3$ indicates that it has undergone a significant change. This change raises the question of the advisability of shipping the roving counter for interlaboratory comparisons without taking special precautions regarding the keeping of its temperature within certain limits. (The shipment to and from the Argonne National Laboratory took place in December.) TABLE VII. Comparison of the Sensitivities(a) of $\mathrm{H}-1$ and NBS-1 for Different Neutron Energies

$\begin{array}{cccc}\frac{\text { Neutron Energy, MeV }}{0.152} & \frac{s(N B S-1)}{0.9961 \pm 0.0005} & & 0.9981 \pm 0.0009 \\ 0.331 & 0.9975 \pm 0.0002 & & 0.9995 \pm 0.0008 \\ 0.690 & 0.9969 \pm 0.0019 & & 0.9989 \pm 0.0020 \\ 1.341 & 0.9972 \pm 0.0005 & & 0.9992 \pm 0.0009 \\ 4.29 & 0.9981 \pm 0.0008 & & 1.0001 \pm 0.0011 \\ 16.92 & 0.9965 \pm 0.0009 & & 0.9986 \pm 0.0012\end{array}$

(a) $r(\mathrm{NBS}-1)=0.9980 \pm 0.0008$ 
TABLE VIII. Comparison of the Sensitivies ${ }^{(a)}$ of $\mathrm{H}-1$ and $\mathrm{H}-2$ for Different Neutron Energies

Neutron Energy, MeV
$\begin{gathered}0.331 \\ 0.690 \\ 16.92\end{gathered}$

$\frac{s(H-2)}{1.003 \pm 0.002}$
$1.006 \pm 0.001$
$1.004 \pm 0.002$

$\frac{w(\mathrm{H}-2)}{1.006 \pm 0.002}$
$1.009 \pm 0.001$
$1.007 \pm 0.002$

(a) $r(H-2)=0.9972 \pm 0.0008$

TABLE IX. Comparison of the Sensitivities of Eight PLC's

\begin{tabular}{|c|c|c|c|c|}
\hline $\mathrm{Y}$ & $r(Y)$ & $s(Y)$ & $w(Y)$ & Date $^{(\mathrm{a})}$ \\
\hline $\mathrm{H}-1$ & 1.000 & 1.000 & 1.000 & $-\cdots$ \\
\hline NBS- 1 & 0.998 & 0.997 & 0.999 & $10-24-60$ \\
\hline $\mathrm{H}-2$ & 0.997 & 1.004 & $1 / 007$ & $10-24-60$ \\
\hline $\mathrm{H}-3$ & 0.997 & 0.990 & 0.993 & $3-9-62$ \\
\hline $\mathrm{H}-4$ & 0.998 & 0.991 & 0.993 & $3-9-62$ \\
\hline $\mathrm{L}-1$ & 0.992 & 0.984 & 0.993 & $3-9-62$ \\
\hline$M L-1$ & 0.990 & 0.987 & 0.997 & $10-8-62$ \\
\hline$A N L-1$ & 0.988 & 0.984 & 0.996 & $12-23-62$ \\
\hline $\mathrm{H}-3$ & 0.995 & 0.996 & 1. 001 & $3-12-63$ \\
\hline $\mathrm{H}-2$ & 0.998 & 1.003 & 1.005 & $3-21-63$ \\
\hline
\end{tabular}

(a) Chosen at about the middle of the period over which the comparison was made

\section{REPRODUCIBILITY OF PLC RESPONSE-ABSOLUTE MEASUREMENTS}

The absolute measurement of the response of a PLC is more difficult and less accurate to make than the relative measurement described in the above section because it is concerned with the constants of neutron sources and is affected by room geometry. Two of the neutron sources will now be selected as standard: the large $\mathrm{Ra}-\gamma-\mathrm{Be}$ source (NBS-I) from the National Bureau of Standards as the external primary standard and the small $\mathrm{PuBe}$ source (M-1045) mounted in its PLC holder from Mound Laboratory as the internal standard. Furthermore, the counter $\mathrm{H}-1$ will be chosen as the standard PLC. 
The objective of this section is to outline a procedure for measuring the absolute response of $\mathrm{H}-1$ to the source NBS-I (and for sources calibrated against NBS-I) relative to its response to M-1045 (and for sources calibrated against M-1045) for a particular room-the low-scattering room of the positive ion accelerator at Hanford.

A parameter, $\underline{\alpha}$, is used to characterize a particular PLC for a particular combination of internal and external sources. It is defined by the equation,

$$
\alpha=\frac{4 \pi b(t) R_{r}(X)}{\varepsilon Q(t) A_{r}(X)}
$$

where $\underline{b}$ is obtained from Equation (11), Q is obtained from Equation (2), $\underline{\varepsilon}$ is obtained from Equation (8), while the reduced ratio, $R_{r}(X)$, and the reduced characteristic rate, $A_{r}(X)$, are defined in terms of ordinary characteristic rates for the internal source $\mathrm{X}$ and the secondary internal standard source M-1045 according to

$$
\dot{\mathrm{A}}_{r}(\mathrm{X})=\frac{\dot{\mathrm{A}}(\mathrm{X}, \mathrm{t})}{1+\mathrm{A} f(\mathrm{t})}
$$

and

$$
\mathrm{R}_{\mathrm{r}}(\mathrm{X})=\dot{\mathrm{A}}_{\mathrm{r}}(\mathrm{X}) / \dot{\mathrm{A}}_{\mathrm{r}}(1045)
$$

The time $\underline{t}$ given in Equation (16) refers to the time between the measurement of $\underline{b}$ and the birthdate of the external source. The time $t$ given in Equation (17) is the time between the measurement of the characteristic rate and the birthdate of the internal source. The parameter $\alpha$ is a quantity that does not depend on the time but does depend on the external source and the PLC.

The factor $\frac{4 \pi \mathrm{b}}{\overline{\mathrm{Q}}}$ appearing in Equation (16) may be regarded as a flux density sensitivity, $\underline{S}$, for a PLC by making the following argument. Let a direct flux density, $\varphi$, produced by a cylindrical source of strength, $Q$, at the effective center of a PLC be calculated from the equation

$$
\psi=\frac{\epsilon Q}{4 \pi(x+c)^{2}}
$$


Let $S$ be defined according to the equation

$$
\mathrm{S}=\frac{\dot{\mathrm{A}}-\mathrm{a}}{\mathrm{C}}
$$

which from Equation (11) leads to a flux density sensitivity, S, which does not depend on the distance $\underline{x}$ :

$$
S=\frac{4 \pi b}{\epsilon Q}
$$

The correction made in Equation (20) for the room-scattered neutron contribution to the counting rate can be regarded in a different way by postulating a room scattered flux density, $\varrho^{\prime}$, according to

$$
\mathrm{cr}=\frac{\mathrm{a}}{\mathrm{b}} \frac{\epsilon \mathrm{Q}}{4 \pi}
$$

and this postulate leads to a third way of expressing $\underline{S}$; namely,

$$
S=\frac{\dot{A}}{\varphi+\varphi^{\prime}}
$$

Finally, because of Equations (16) and (21) the result,

$$
S=\frac{\alpha \dot{A}_{r}(X)}{R(X)}
$$

is obtained. For the internal source M-246 the flux density sensitivity becomes

$$
S=\frac{\alpha \dot{A}_{r}(246)}{1.479}
$$

with the value, $R_{r}(246)=1.479$ (taken from Table V).

Because many measurements were made in this work on PLC's other than $\mathrm{H}-1$, a for counter $\mathrm{Y}$ was expressed in terms of its value for $\mathrm{H}-1$ by extending Equation (15) to give

$$
w(Y) \cong \frac{\alpha(Y)}{\alpha(H-1)}
$$

and combining it with Equation (16) to yield

$$
\alpha(\mathrm{H}-1)=\frac{4 \pi \mathrm{b}}{\varepsilon \mathrm{Q}} \frac{1.479}{\mathrm{~A}_{\mathrm{r}}(246)} \frac{1}{\mathrm{w}(\mathrm{Y})}
$$

where all measurements are now made on $\mathrm{Y}$, calibrated with the source $\mathrm{M}-246$. 
BNWL-260

Equation (27), when applied to ML-1, yields

$$
\begin{aligned}
\alpha(\mathrm{H}-1) & =\frac{\mathrm{b}}{\mathrm{Q} / 4 \pi} \frac{1}{\mathrm{~A}_{r}(1045)} \frac{1}{\mathrm{w}(\mathrm{ML}-1)} \\
& =\frac{(1657 \pm 12) \times 10^{5}}{7.6536 \times 10^{5}} \times \frac{1}{30283} \times \frac{1}{0 . \overline{997}} \\
& =(7171 \pm 52) \times 10^{-6}
\end{aligned}
$$

in fairly good agreement with $\alpha(\mathrm{H}-1)=(7094 \pm 43) \times 10^{-6}$

for the source M-199 and with $\alpha(\mathrm{H}-1)=(6980 \pm 36) \times 10^{-6}$

for the source M-590. (See Table X.)

The reproducibility of $\mathrm{PLC}^{\prime} \mathrm{s}$ containing different $\mathrm{BF}_{3}$ tubes was determined by comparing their responses measured in the inverse square runs taken with the different radioactive neutron sources.

However, these measurements based on the source characteristics given in Table $\mathrm{V}$ also served to establish the absolute responses of the PLC's.

Three constants ( $\underline{a}, \underline{b}$, and $\underline{c}$ ) were measured in each inverse square run by making a least squares fit of the count rate data to Equation (11). Reproducibility was sought for the $\underline{\alpha}$, $\underline{a} / \underline{b}$, and $\underline{\mathrm{c}}$ quantities from these measurements; the flux density sensitivity $\underline{S}$ is to be calculated from $\underline{\alpha}$ according to Equation (24). Values of a for $Y$ were reduced to values of $\alpha(H-1)$ from Equations(15) and (27).

Table $\mathrm{X}$ gives the results of the various determinations of $\alpha, a / b$, and $c$ which were obtained from the inverse square data. The last column is the value of the average neutron energy.

The values of $\alpha(H-1)$ given in Table $X$ for the sources $M-199$ and M-590 were determined from measurements taken on the $\mathrm{H}-1$, $\mathrm{H}-2, \mathrm{H}-4$, and $\mathrm{L}-1 \mathrm{PLC}^{\prime} \mathrm{s}$, and on $\mathrm{BF}_{3}$ tubes having different wall material -brass, aluminum, and copper-are plotted in Figure 11. One of the brass $\mathrm{BF}_{3}$ tubes (Run No. 75) contained the same $\mathrm{BF}_{3}$ gas pressure, 250 Torr; but the gas was depleted in its $\mathrm{B}^{10}$ content compared to the usual mixture of $96 \% \mathrm{~B}^{10}$ and $4 \% \mathrm{~B}^{11}$. The standard 
errors given in Table $X$ are measures of the reproducibility of the measurements taken on the counters and are to be compared with the standard errors obtained for the individual points (See Figure 11) from the least squares analyses of the inverse square data. In calculating the average value of $\alpha(\mathrm{H} 1), 7094 \times 10^{-6}$, for the source $M-199$, the point for Run No. 66 was omitted; and two points, not shown in Figure 11, were included from Run No. 39 and Run No. 44.

TABLEX. Constants ${ }^{(a)}$ of the PLC for Different Radioactive Neutron Sources

\begin{tabular}{|c|c|c|c|c|c|}
\hline Source & Runs & $10^{6} \sim(\mathrm{H}-1)$ & $10^{6} \mathrm{a} / \mathrm{b}$ & $\mathrm{c}(\mathrm{cm})$ & $\mathrm{E}(\mathrm{MeV})$ \\
\hline$M-199$ & 8 & $7094+43$ & $2.50 \pm 0.15$ & $11.7 \pm 0.2$ & 3.9 \\
\hline$M-590$ & 15 & $6980+36$ & $2.46 \pm 0.11$ & $11.7 \pm 0.2$ & 3.9 \\
\hline $\mathrm{NBS}-\mathrm{H}$ & 1 & $7023+39$ & $2.67 \pm 0.40$ & $12.4 \pm 0.2$ & 4.2 \\
\hline $\mathrm{PuF}_{4}^{-2}$ & 4 & $7398+33$ & $2.48 \pm 0.09$ & $9.8 \pm 0.2$ & 1.2 \\
\hline NBS-II & 4 & $7091+41$ & $2.86 \pm 0.10$ & $8.0 \pm 0.1$ & 0.2 \\
\hline $\mathrm{RaBe} 68 \mathrm{~B}$ & 4 & $7172+13$ & $2.45 \pm 0.09$ & $11.6 \pm 0.1$ & 3.6 \\
\hline $\mathrm{SbBe}-4$ & 1 & -- & $1.74 \pm 0.51$ & $8.0 \pm 0.3$ & 0.025 \\
\hline
\end{tabular}

(a) Errors for various quantities are based on the reproducibility of different observations unless only one observation is made; in this case the error is given from a single least squares analysis.

Two quantities, $a / b$ and $c$, appearing in Table $X$ are shown in Figure 12 plotted as a function of the average neutron energy, $\bar{E}$, for the different radioactive neutron sources and yield the results,

$$
a / b=2.5 \times 10^{-6}
$$

and

$$
c=7.8+1.1 \mathrm{E} \text {. }
$$

This linear equation is to be compared with Equation (12) for LC No. 2 and with Equation (13) for the Harwell long counter.

The discrepancy between the two values of $\alpha,(7079 \pm 43) \times 10^{6}$ and $(6980 \pm 36) \times 10^{6}$, for the sources $M-199$ and $M-590$ will serve as an example around which a discussion of errors can be centered. This 
discrepancy initiated a careful study of errors at both Hanford and at Mound Laboratory and resulted in a better understanding of them. Equation (27) shows the various quantities upon which $\underline{\alpha}$ depends and the estimated errors for each quantity will now be made.

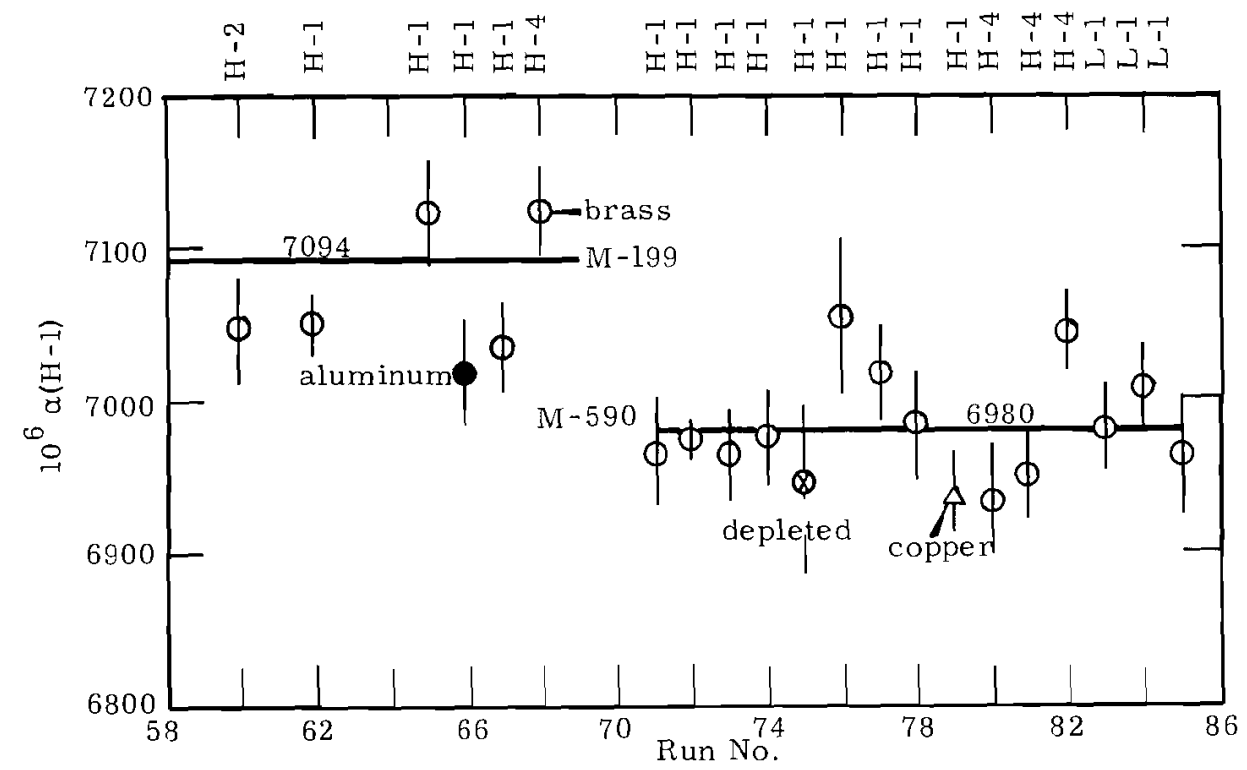

FIGURE 11. Results of the Determination of $\alpha(H-1)$ from Data Taken with Four Different PLC's, with $\mathrm{BF}_{3}$ Tubes Having Different Wall Materials and Isotopic Gas Composition, and with Two Different Neutron Sources. (The standard errors shown were obtained from the least squares analysis of the inverse square data obtained for each run.)

The errors stated for $\alpha$ in Table $X$ were based on the reproducibility of $\underline{\alpha}$ obtained from a number of inverse square runs. The errors shown for the different values of $\underline{\alpha}$ given in Figure 11 were based only on the errors calculated for $\underline{b}$. Clearly, the errors in $\underline{b}$ do not account for the discrepancy between the values of $\underline{\alpha}$ for the two neutron sources.

Measurements of $\underline{\varepsilon}$ cannot account for the discrepancy because values measured at Hanford and at Mound Laboratory all agreed to within $0.2 \%$. An error in the factor 1.479 produces the same error in all values determined for $\underline{\alpha}$. It seems unlikely that there are errors in the reduced characteristic rates $\dot{A}_{r}(246)$ because characteristic rates can be measured to within $\pm 0.1 \%$ quite easily and because the time span of the inverse square measurements was no longer than 18 mo over 
which the errors caused by the uncertainties in the growth rates would only, at most, amount to a few tenths of $1 \%$. The error in the comparison index, $\mathrm{W}(\mathrm{Y})$, for $\mathrm{Y}$ is estimated to be no more than $\pm 0.1 \%$. Thus, the errors in the remaining quantity $\underline{Q}$ must be responsible for the discrepancy between the two values of $\underline{\alpha}$.
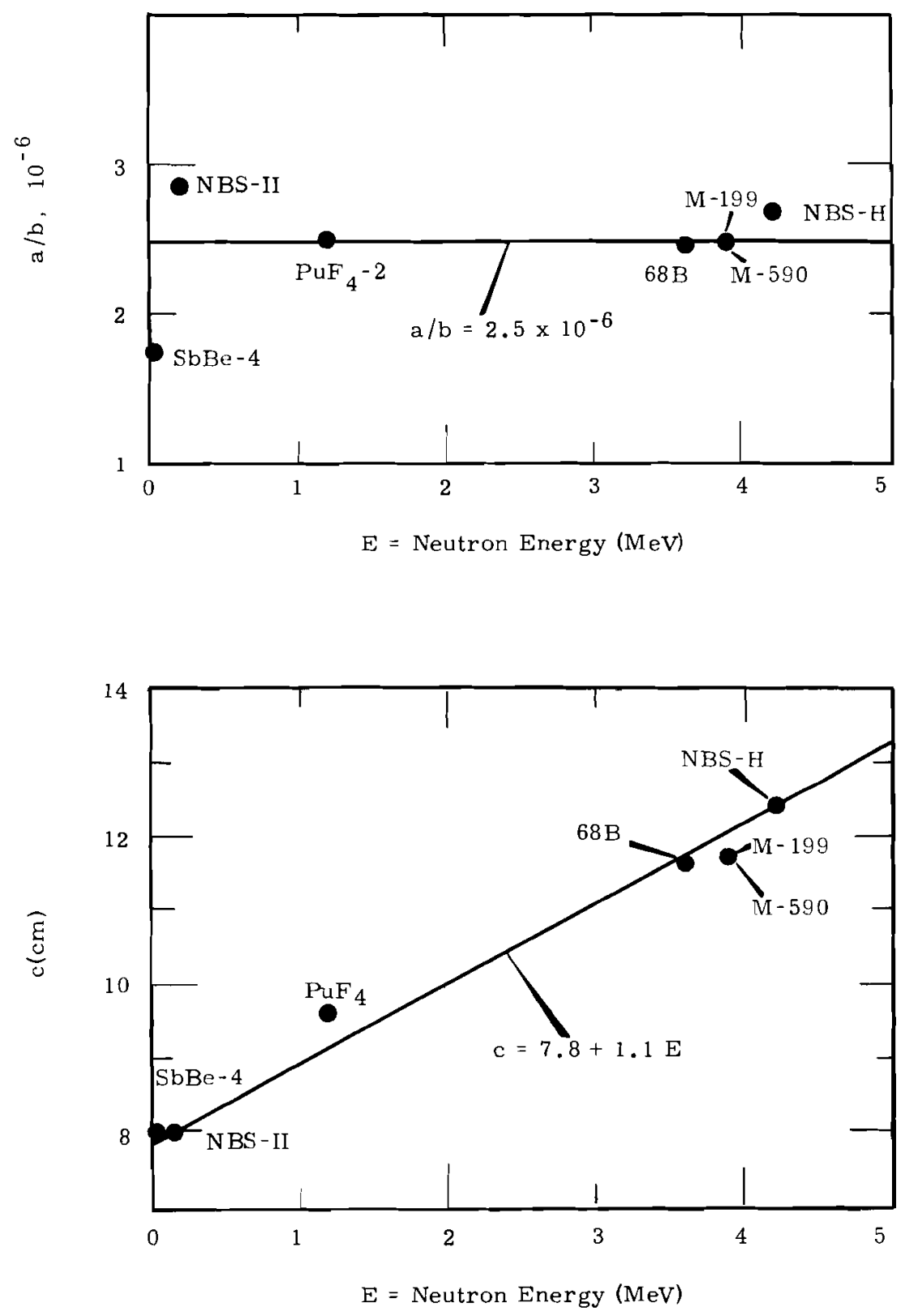

FIGURE 12. Two Quantitites, $10^{6} \mathrm{a} / \mathrm{b}$ and $c$, for a PLC Exposed to Different Radioactive Neutron Sources 
To investigate the possibility that errors in $Q$ were responsible for the discrepancy, values of the ratio $A(590) / Q(199)$ were determined from data obtained at Mound Laboratory, at Hanford, and at the National Bureau of Standards. These data yielded the three values, 1.075, 1.089, and 1.103 , respectively, after corrections had been made for the time dependence of the neutron emission rates to one particular time. The difference between the first two values, amounting to $1.4 \%$, has not been resolved in spite of a diligent effort to explain it. Such a large difference is surprising because the ratios were measured by the same PLC comparison method and should have given agreement to within $\pm 0.2 \%$. However, as equally strange is the fact that the NBS calibration, making use of the manganese sulfate bath technique in comparing M-199 with M-591 at different times, should yield a different value of Q(590)/Q(199). All these results depend on the accuracy with which Q(590) and Q(591) were compared by the PLC technique at Mound Laboratory.

The discrepancy between the effect of room scattered neutrons on the response of a PLC as exhibited by the difference between the parameters $\underline{a}$ and $\underline{a}^{\prime}$ is not surprising from consideration of the fact that Equation (11) is an empirical equation. The measurement of a is more difficult to make than the measurement of $\mathrm{a}^{\prime}$, but the former leads to a closer fit to the inverse square data. Furthermore, the use of a leads to good agreement in values of $\underline{\alpha}$ obtained in different laboratories. In the case of the measurement made of $\underline{\alpha}$ at the Mound Laboratory, a shadow shield was employed to measure the change of a with changing $\underline{x}$ but was not used in determining its absolute value. Thus, for radioactive sourçes the quantity, $\underline{a}$, yields the best results.

The agreement between calculated and measured values of the relative efficiency as given by Table XI is within $1 \%$, a somewhat remarkable result in view of the composite curve assumed in Figure 7 for LC No. 2. This result demonstrates the good accuracy which can be obtained with a PLC and radioactive neutron sources. 
TABLE XI. Comparison Between Measured and Calculated Values of the Average Relative Efficiency of a PLC for Different Radioactive Neutron Source

\begin{tabular}{|c|c|c|c|c|}
\hline Source & $10^{6} \alpha(\mathrm{H}-1)$ & $\underline{\bar{E}}, \mathrm{MeV}$ & $\bar{\eta}_{f}^{\prime}(\bar{E}, 87.9)$ & $\bar{\eta}^{\prime}(\overline{\mathrm{E}}, 87.9)$ \\
\hline M-199 & 7094 & 3.9 & 0.95 & 0.96 \\
\hline$M-590$ & 6980 & 3.9 & 0.95 & $0.95^{(\mathrm{a})}$ \\
\hline $\mathrm{NBS}-\mathrm{H}$ & 7023 & 4. 2 & 0.95 & 0.96 \\
\hline $\mathrm{PuF}_{4-2}$ & 7398 & 1.2 & 1.00 & 1.01 \\
\hline NBS-II & 7091 & 0.2 & 0.96 & 0.96 \\
\hline $\mathrm{RaBe} 68 \mathrm{~B}$ & 7172 & 3.6 & 0.96 & 0.97 \\
\hline
\end{tabular}

(a) This value was chosen to agree with calculated value; other values were determined from $\bar{\eta}^{\prime}(\overline{\mathrm{E}}, 87.9)=0.95 \propto /\left(6980 \times 10^{-5}\right)$.

Figure 11 shows the only data point (triangle) obta ined for $\alpha$ with a copper $\mathrm{BF}_{3}$ tube, which yielded $\alpha=(6937 \pm 36) \times 10^{6}$ for the source $\mathrm{M}-590$. Unfortunately, this particular tube had not been specifically designed for the PLC work; and not until 18 mo later were three tubes obtained of precisely the correct size for use with the PLC.

\section{DERIVATION OF THE BF BUBE SENSITIVITY $_{3}$}

The equations derived in the Reproducibility of PLC ResponseAbsolute Measurements Section for radioactive neutron sources for one angle, i. e., $\theta=90^{\circ}$, are now to be extended to accelerator neutrons emerging at an angle $\theta$ with respect to the beam striking the target as follows. Let $\mathrm{k} \sigma_{\mathrm{T}}$ and $4 \pi \sigma(\theta) / \sigma_{\mathrm{T}}$ be substituted for the emission rate $\underline{\mathrm{Q}}$ and the asymetry ratio $\epsilon(\theta) . \sigma(\theta)$ is the differential cross section, $\sigma_{\mathrm{T}}$ is the total cross section, and $\mathrm{k}$ is a constant depending on the target material and the beam current. The following equations result:

$$
\begin{aligned}
\varphi & =\frac{\mathrm{k} \sigma(\theta)}{(\mathrm{x}+\mathrm{c})^{2}}, \\
S & =\frac{\mathrm{b}}{\mathrm{k} \sigma(\theta)} \\
\varphi^{\prime} & =\mathrm{k} \sigma(\theta) \frac{\mathrm{a}}{\mathrm{b}},
\end{aligned}
$$


A distance-dependent flux-density sensitivity, $\underline{S}^{\prime}$, is now defined by

$$
S^{\prime}=\frac{\dot{A}}{\psi} \text {. }
$$

If Equation (11) is assumed to hold true for accelerator produced neutrons, then $S^{\prime}$ can be related to the distance-independent flux-density sensitivity,

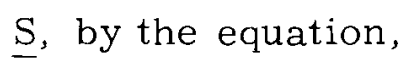

$$
S^{\prime}=S\left\{1+\frac{a}{b}(x+c)^{2}\right\} \text {. }
$$

Furthermore, the relative efficiencies, $\eta(E)$ and $\eta^{\prime}(E, x)$, and a $B F_{3}$ tube sensitivity, $S_{0}$, which do not depend upon $E$ or $x$, can be defined by the equations

$$
\begin{aligned}
S(E) & =S_{O} r_{1}(E) \\
S^{\prime}(E, x) & =S_{O} \eta^{\prime}(E, x) .
\end{aligned}
$$

Finally, the equation

follows readily.

$$
\eta^{\prime}(E, x)=\eta(E)\left\{1+\frac{a}{b}(x+c)^{2}\right\}
$$

A procedure, based on the experimental data presented in the Energy Response of a PLC Relative to LC No. 2 Section, will now be presented for calculating the tube sensitivity $\mathrm{S}_{\mathrm{O}}$ for a particular $\mathrm{BF}_{3}$ tube G-15872. The relative efficiency curve given in Figure 9 when multiplied by $\xi(E) / \xi(1.5)$ (see Figure 10) yields the two curves shown in Figure 13 for the angles $\theta=45^{\circ}$ and $\theta=75^{\circ}$. These curves are to be interpreted as plots of the relative efficiency $\eta^{\prime}(E, 87.9)$ for the PLC. Average values of the relative efficiency $\bar{\eta}^{\prime}(\overline{\mathrm{E}}, 87.9)$ were then calculated from the normalized spectral distribution function $N(E)$ for each of the various radioactive neutron sources listed in Table $\mathrm{X}$ according to the formula

$$
\bar{\eta}^{\prime}(\bar{E}, 87.9)=\int_{O}^{\infty} \eta^{\prime}(87.9, E) N(E) d E
$$

and for the relative efficiency curve measured with $\theta_{1}=\theta_{2}=75^{\circ}$. The results are given in the fourth column of Table XI. One of these results $\bar{\eta}^{\prime}(3.9,87.9)=0.95$, for the source $M-590$ was selected as a starting value for $\bar{\eta}^{\prime}(3.9,87.9)$ from which the entries in the fifth column were calculated 
according to $\bar{\eta}^{\prime}(E, 87.9)=0.95 \alpha /\left(6980 \times 10^{-6}\right)$. The good agreement between the results obtained in the fourth and fifth columns shows that the relative efficiency curve given with $\theta_{1}=\theta_{2}=75^{\circ}$ is satisfactory when applied to radioactive neutron sources.

The relative efficiency $\bar{\eta}^{\prime}=0.95$ for the source $M \cdot 590$ will now be employed to calculate $\mathrm{S}_{\mathrm{O}}$ for the $\mathrm{BF}_{3}$ tube $\mathrm{G}-14023$ from measurements taken on the reduced characteristic rate, 42282 counts/min, taken with $\mathrm{H}-1$ for the source $\mathrm{M}-246$ to yield

$$
\bar{\eta}^{\prime}=1.025 \bar{\eta}
$$

and

$$
S=S_{O}=0.928 S_{O}=\frac{6980 \times 10^{-6} \times 42282}{1479}
$$

or

$$
\left.\mathrm{S}_{\mathrm{O}}=215 \text { (counts } / \mathrm{min}\right) /\left(\text { neutron } / \mathrm{cm}^{2}-\mathrm{sec}\right)
$$

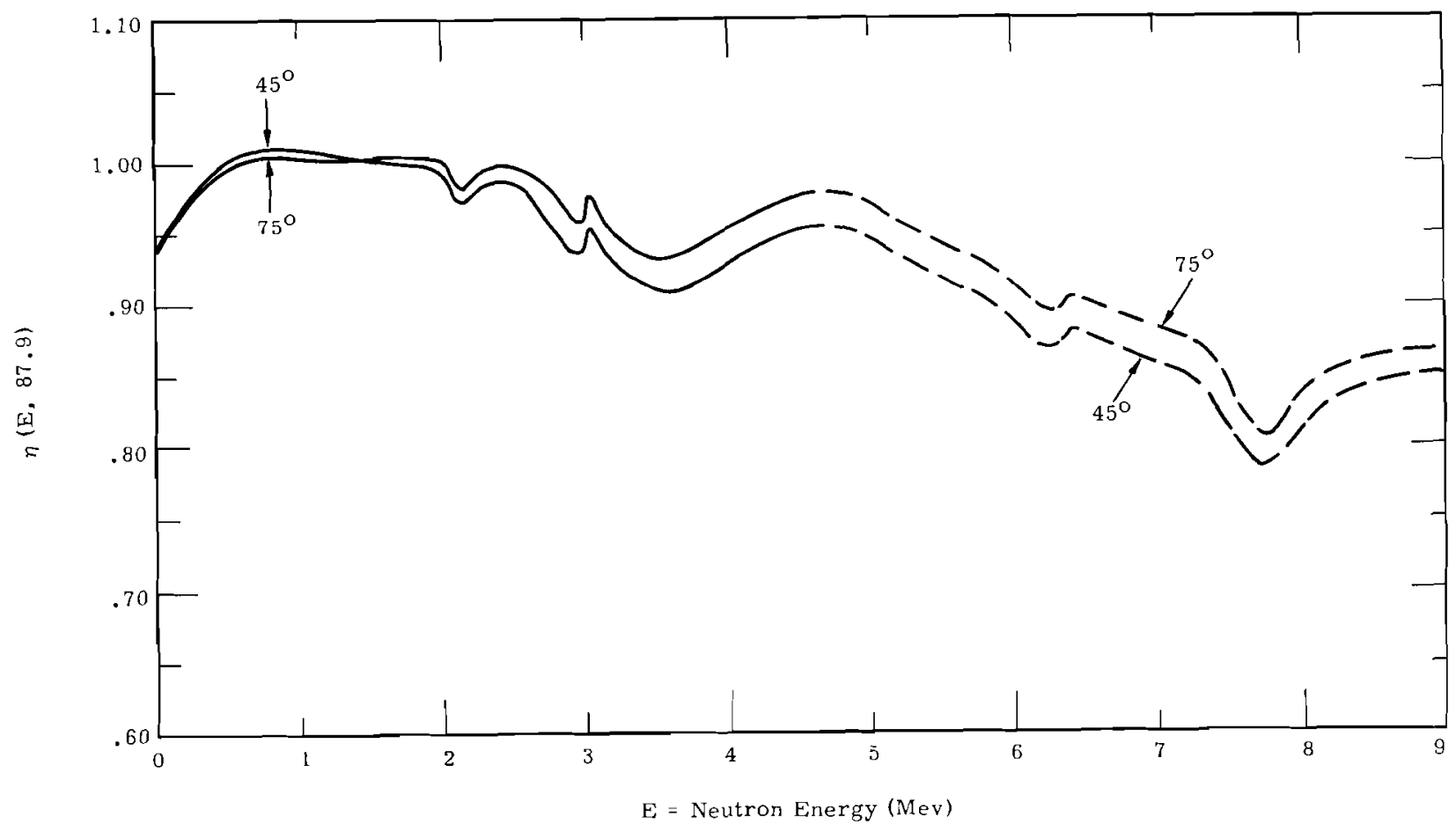

FIGURE 13. Relative Efficiency, $\eta(E, 87.9)$, Measured for a PLC at Two Different Angles, $45^{\circ}$ and $75^{\circ}$ 


\section{MEASUREMENTS OF THE EFFECT \\ OF FINITE COUNTER SIZE}

Because the data obtained with the procedure outlined in the Energy Response of a PLC Re-ative to LC No. 2 Section produced two slightly different values of the ratio, $\xi=$ (NBS-1 courits/(LC No. 2 counts), at each energy for the two different angies, $45^{\circ}$ and $75^{\circ}$, an experiment was deivsed to see if these results were caused by comparing different finite counters in nonuniform neutron radiation fields. In this experiment $\mathrm{H}-1$ was suspended from the instrument carrier and counts were taken at different angles. The monitor counter, a 5 in. diam NE404 detector (lucite plus activated zinc sulfide) viewed by a 5 in. photomultiplier, was placed on a line making an angle of about $135^{\circ}$ with the deuteron beam used in the experiment. Two sets of angular distribution data were obtained: one set was obtained for a deuteron energy of $0.8 \mathrm{MeV}$ and the other for a deuteron energy of 2. $0 \mathrm{MeV}$ with the deuterons producing neutrons in a DZr target. The object of the experiment was to compare normalized ratios of counts corrected for the variation of the differential cross sections, $\sigma\left(\theta_{1}, 0.8\right)$ and $\sigma\left(\theta_{2}, 2.0\right)(20)$, where $\theta_{1}$ and $\theta_{2}$ are paired to yield the same neutron energy (21). One quantity (14) is defined as

$$
u_{1}=A\left(\theta_{1}, 0.8\right) / 0\left(\theta_{1}, 0.8\right) \quad A_{M}\left(135^{\circ}, 0.8\right)
$$

and the other quantity is defined as

$$
u_{2}=A\left(\theta_{2}, 2.0\right) / \sigma\left(\theta_{2}, 2.0\right) \quad A_{M}\left(135^{\circ}, 2.0\right)
$$

An ideal point counter should yield the ratio, $u_{1} / u_{2}$, to be constant as long as $\theta_{1}$ and $\theta_{2}$ are paired to give the same neutron energy.

Figure 14 shows a plot of the neutron angle $\theta_{1}$ against the neutron energy when a thin $\mathrm{DZr}$ target is bombarded with $0.8 \mathrm{MeV}$ deuterons. It also shows a plot of the neutron angle $\theta_{2}$ against the neutron energy when the same target is bombarded with $2.0 \mathrm{MeV}$ deuterons. Finally, the ratio $u_{1} / u_{2}$, associated with $\theta_{1}$ and $\theta_{2}$ according to Equations (38) and (39), is plotted as a function of the neutron energy. This ratio exhibits an extreme variation of over $30 \%$ and demonstrates a serious finite-size effect for the PLC's. For small detectors the ratio should be near unity. Similar results were obtained when a $\mathrm{D}_{2}$ 
gas target was used in place of the DZr target. Additional work with $T(p, n)$ neutrons from TTi target demonstrated the same kind of effect.

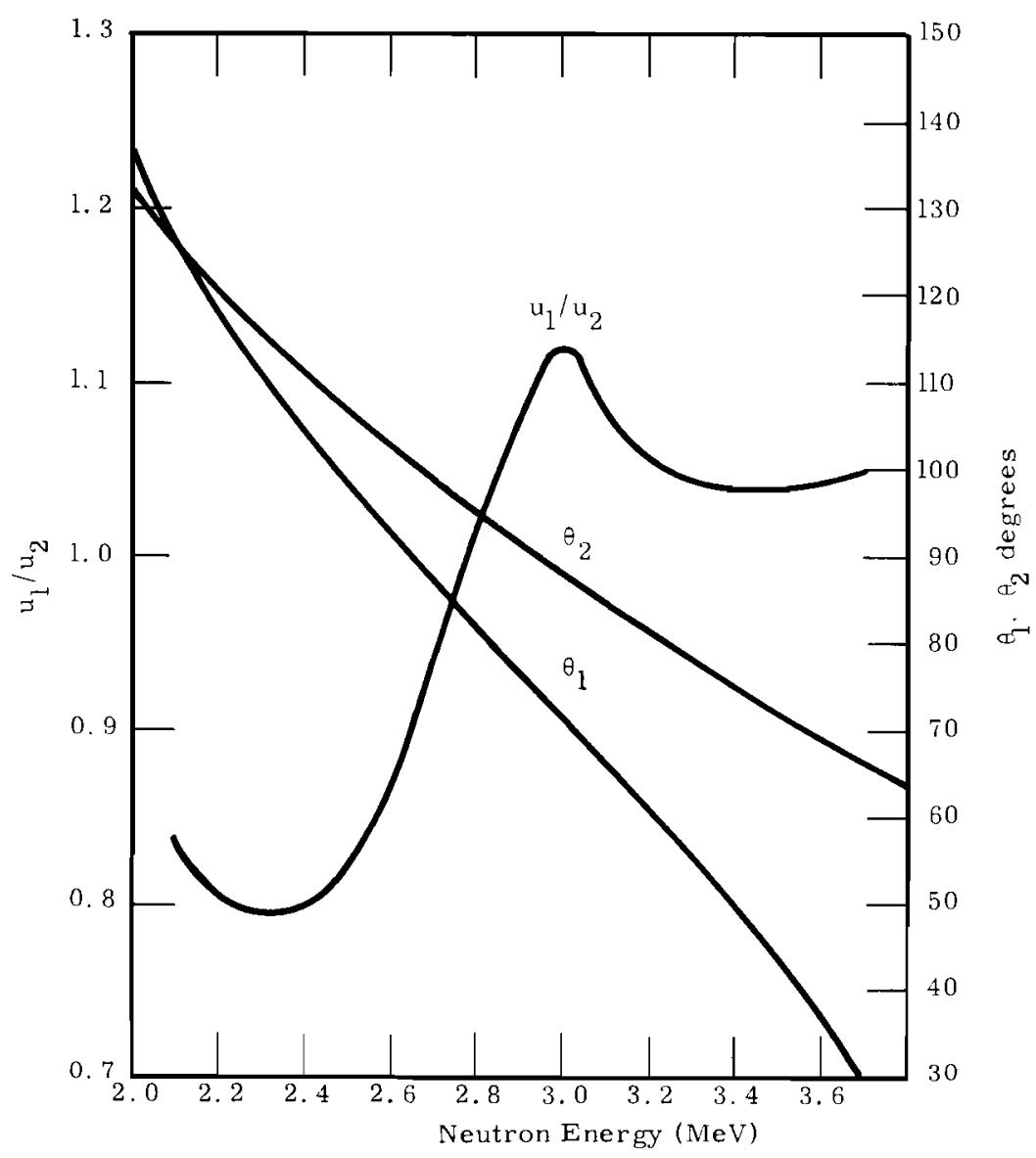

FIGURE 14. Plots of $u_{1} / u_{2}, \theta_{1}$, and $\theta_{2}$ as Functions of the Nezutron Energy for NBS-1 Irradiated with Neutrons from the $\mathrm{D}(\mathrm{d}, \mathrm{n}) \mathrm{He}^{3}$

RELATIVE RESPONSE OF A PLC TO TWO NEUTRON SOURCES IN DIFFERENT KINDS OF SCATTERING GEOMETRY

An experiment was performed to compare the responses of the PLC to the external PuBe neutron source M-1220 and to the internal PuBe neutron source $M-246^{\prime}$ in different kinds of scattering geometry. The results of this experiment are shown in Table XII. Seven different geometries were tested in which the source-detector distance was kept at $100 \mathrm{~cm}$ and the horizontal source-detector line was always kept 42 in. above the floor level. Measurements of the characteristic rates were taken for each 
geometry. When $\mathrm{H}-2$ was used in place of $\mathrm{H}-1$ the relative counting rates were corrected for the slightly different sensitivity of $\mathrm{H}-2$ (See Table IX) to give the values enclosed in parenthesis for $\mathrm{H}-1$. In each case the count-rate data included at least one million counts.

TABLE XII. Relative Response of a PLC to Two Neutron Sources in Different Kinds of Scattering Geometry

Geometry Designation

\begin{tabular}{cc} 
Relative Counting Rate for Neutron Source & $(a)$ \\
\hline Internal & External \\
Source & Source \\
\hline
\end{tabular}

$1.000^{(\mathrm{c})}$

$1.011(1.004)$

$1.015(1.008)$

$1.035(1.028)$

1. 048

$1.058(1.051)$

1. $208(1.201)$

(a) $80 \mathrm{~g}$ PuBe source, $\mathrm{M}-1220$, set at distance $\mathrm{x}+\mathrm{c}=88.3+11.7$ $=100 \mathrm{~cm}$ from PLC with source-detector line $42 \mathrm{in}$. above floor (or ground).

(b)

(c) ${ }_{\text {characteristic rate }=42135 \mathrm{counts} / \mathrm{min}}$

NOTE:

$1 \mathrm{H}-1$ suspended by instrument carrier over pit covering the grating floor of the accelerator building.

$2 \mathrm{H}-2$ on adjustable aluminum stand on grating floor.

$3 \mathrm{H}-2$ on stand outside over gravel covered ground.

$4 \mathrm{H}-2$ on stand on concrete floor in large room with a high ceiling.

$5 \mathrm{H}-1$ on stand in medium-size room housing electron accelerator and having thick concrete walls.

$6 \mathrm{H}-2$ on stand in accelerator control room with scattering material nearby.

$7 \mathrm{H}-2$ on stand in small room having concrete walls $4 \mathrm{ft}$ thick. 
The characteristic rates are not significantly different in the different geometries but the external rates are different with the lowest rate occurring for the geometry employed for the work reported in this paper. The geometry giving the lowest rate is interpreted to be the one giving the least proportion of scattered neutrons.

USE OF THE PLC WITH ACCELERATOR PRODUCED NEUTRONS

The rather crude energy dependence calibration in Figure 13 of the PLC gives surprisingly good results as demonstrated in Table XI with radioactive neutron sources in spite of the finite size of the PLC. Thus, the PLC can be used to measure neutron flux densities from radioactive neutron sources having known energy spectra with quite good accuracy. However, the finite size of the PLC seriously limits the accuracy of the measurements of the flux density for accelerator produced neutrons. Figures 10,13, and 14 demonstrated the problem which arises when a PLC is employed to measure monoenergetic neutrons from the $D(d, n)$ reaction. It seems quite certain from these results that an accurate energy calibration of the PLC is not possible. Nevertheless, two procedures will be proposed for determining flux densities of monoenergetic neutrons: one will give approximate results with little effort, and the other will give accurate results with considerable effort.

The first procedure for measuring the flux density $\theta$ makes use of differential cross section data and of the relative efficiency as given in Figure 13 as a function of the neutron energy. The PLC is pointed at the accelerator target and held at one point, $\left(x_{1}, \theta_{1}\right)$, throughout the measurements. The counting rate $\dot{A}_{1}$ is measured. The flux density $\varphi$ at any point, $(r, 0)$, is given by

$$
\varphi=\frac{k \sigma(\theta)}{r^{2}}
$$

which is obtained from Equation (29) by substituting $\underline{r}$ for $x+c$. The quantity, $k$, can be determined from the equation, 


$$
\mathrm{k}=\frac{\left(\mathrm{x}_{1}+\mathrm{c}\right)^{2} \dot{\mathrm{A}}_{1}}{\sigma\left(\theta_{1}\right) \mathrm{S}_{1}^{1}},
$$

which results from the application of equations (29) and (32). Finally, the flux density $\varphi$ is given by

$$
\varphi=\left(\frac{x_{1}+c}{r}\right)^{2} \frac{\sigma(\theta)}{\sigma\left(\theta_{1}\right)} \frac{\dot{A}_{1}}{S_{1}^{\prime}}
$$

where

$$
S_{1}^{\prime}=S_{0} \eta^{\prime}(E, x)
$$

and $\eta^{\prime}(E, x)$ is obtained from Figure 13. The error in making this last step is considerable, but the procedure of using a fixed PLC and differential cross section data marks an improvement over the common way of using a long counter at various angles and distances because the cross section data are usually obtained with small detectors.

The second procedure for measuring $\varphi$ avoids the use of Equation (43) and makes use of Equations (23), (24), and (25) to yield

$$
\varphi=\left(\frac{x_{1}+c}{r}\right)^{2} \frac{\sigma(\theta)}{\sigma\left(\theta_{1}\right)} \frac{\dot{A}_{1}}{\dot{A}_{r}(X)} \frac{R(X)}{\alpha}
$$

where $\alpha$ is to be regarded as not simply depending on the neutron energy $\underline{E}$ but on the bombarding energy $E_{1}$ on the angle $\theta_{1}$ and on the particular reaction employed. In fact, Equation (44) will be generalized to read

$$
\varphi=\frac{F\left(x_{1}, \theta_{1}, E_{1}, \theta\right)}{r^{2}} \underset{\dot{A}_{r}(X)}{R(X)} \dot{A}_{1} .
$$

The procedure for measuring $\varphi$ is to measure it carefully in one laboratory with a target and target holder of reproducible design* and with a precision instrument such as the counter telescope. Thus, $F\left(x_{1}, \theta_{1}\right.$, $\left.E_{1}, \theta\right)$ is measured as a function of $\theta$ for the fixed values of $x_{1}$ and $\theta_{1}$,

*One of the requirements of this design is that $\varphi(\theta)=\varphi(-\theta)$. The design should be checked especially for parts which do not yield the same attenuations of the neutron intensity when exchanged with spare parts. 
say, $x_{1}=87.9 \mathrm{~cm}$, and $\theta_{1}=45^{\circ}$, and for selected values of $E_{1}$ and selected neutron producing reactions. These seiections will now be considered.

A problem exists (Reference 22) in producing adequate intensities of monoenergetic neutrons over a wide range of neutron energies because an important energy gap exists between 7.8 and $12 \mathrm{MeV}$. This problem is illustrated with the aid of Figure 15 in which the neutron energy is plotted against the bcmbarding energy for the five commonly used neutron producing reactions: $\mathrm{Li}^{7}(\mathrm{p}, \mathrm{n}) \mathrm{Be}^{i}, \mathrm{~T}(\mathrm{p}, \mathrm{n}) \mathrm{He}^{3}, \mathrm{C}^{12}\left(\mathrm{~d}, \mathrm{r}_{1}\right) \mathrm{N}^{13}, \mathrm{D}(\mathrm{d}, \mathrm{n}) \mathrm{He}^{3}$, and $\mathrm{T}(\mathrm{d}, \mathrm{n}) \mathrm{He}^{4}$. Tre upper and lower bounds of each enclosed region were calculated for $\theta=0^{\circ}$ and $\theta=180^{\circ}$ while the bound on the right of each enclosed region is set to avoid inierierence from neutrons not associated with the ground state or from competing reactions.

For the $\mathrm{Li}^{7}(\hat{\mathrm{p}}, \mathrm{n}) \mathrm{Be}^{7}$ reaction, if the proton energy exceeds 2. $4 \mathrm{MeV}$, neutrons are produced on differen: energies depending upon whether $\mathrm{Be}^{7}$ is left in its first excited state or in its ground state. For the $T(p, n) H e^{3}$ reaction, the interfering reaction of $T(p, n p) D$ has its threshold at $8.4 \mathrm{MeV}$. In the $\mathrm{C}^{12}\left(\mathrm{~d}, \mathrm{n}: \mathrm{N}^{13}\right.$ reaction, if the deuteron energy exceeds 3.09 MeV, neutrons are produced of different energies depending upon on whether $\mathrm{N}^{13}$ is ieft in its first excited state or in its ground state. In the $\mathrm{D}(\mathrm{d}, \mathrm{n}) \mathrm{He}^{3}$ reaction, the interfering reaction of Did, np)D has its threshold at 4. $45 \mathrm{MeV}$. Finally, in the $\mathrm{T}(\mathrm{d}, \mathrm{n}) \mathrm{He}^{3}$ reaction, the interfering reaction of the $T(d, n p) T$ reaction has its threshold at 3.71 MeV. Thus, the monoenergetic neutrons have energies limited to the values restricted by the regions shown in Figure 15.

Two striking facts can be deduced from Figure 15. The first is the complete absence of monoenergetic rieutrons between 7.8 and $12 \mathrm{MeV}$; the second is that the entire accessible range of energies is available to an accelerator which has a capability of energies up to 4. $45 \mathrm{MeV}$. Figure 16 shows how a $4.4 \mathrm{MeV}$ accelerator can be operated to produce neutrons by continuously varying the angle and by using the bombarding energies $1.0,2.0,3.0,3.7,4.0$, and $4.4 \mathrm{MeV}$. These particular 
energies were selected to obtain a good overlapping of the bombarding energies which can be obtained with nominal $1.0,2.0,3.0,4.0$, and 5. $0 \mathrm{MeV}$ accelerators. Some redundancy exists through the use of the $\mathrm{C}^{12}(\mathrm{~d}, \mathrm{n}) \mathrm{N}^{13}$ reaction to reduce the neutron energy gap existing for a 2. $0 \mathrm{MeV}$ accelerator.

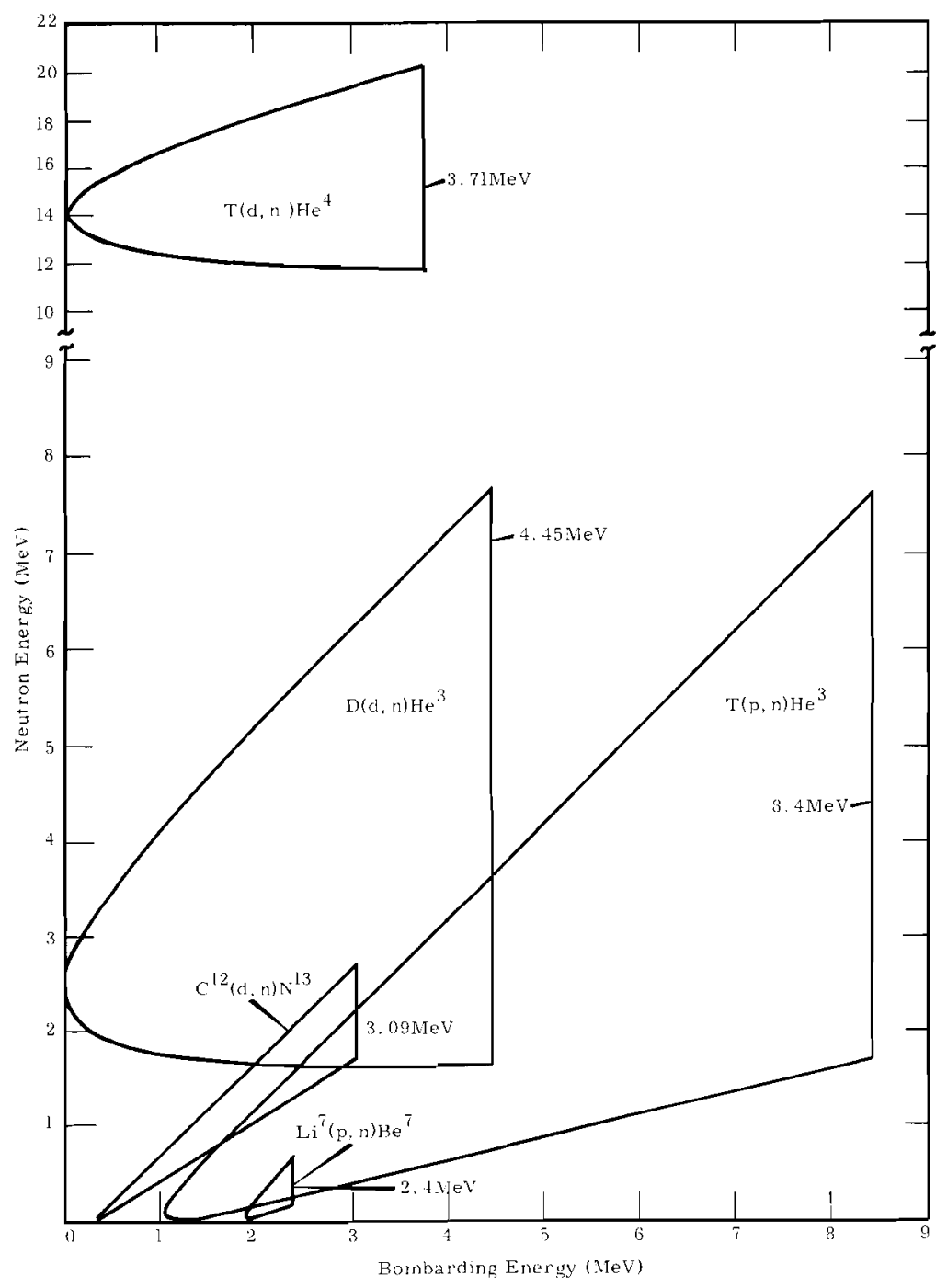

FIGURE 15. Monoenergetic Neutrons Available for Five Commonly Used Neutron Producing Reactions 


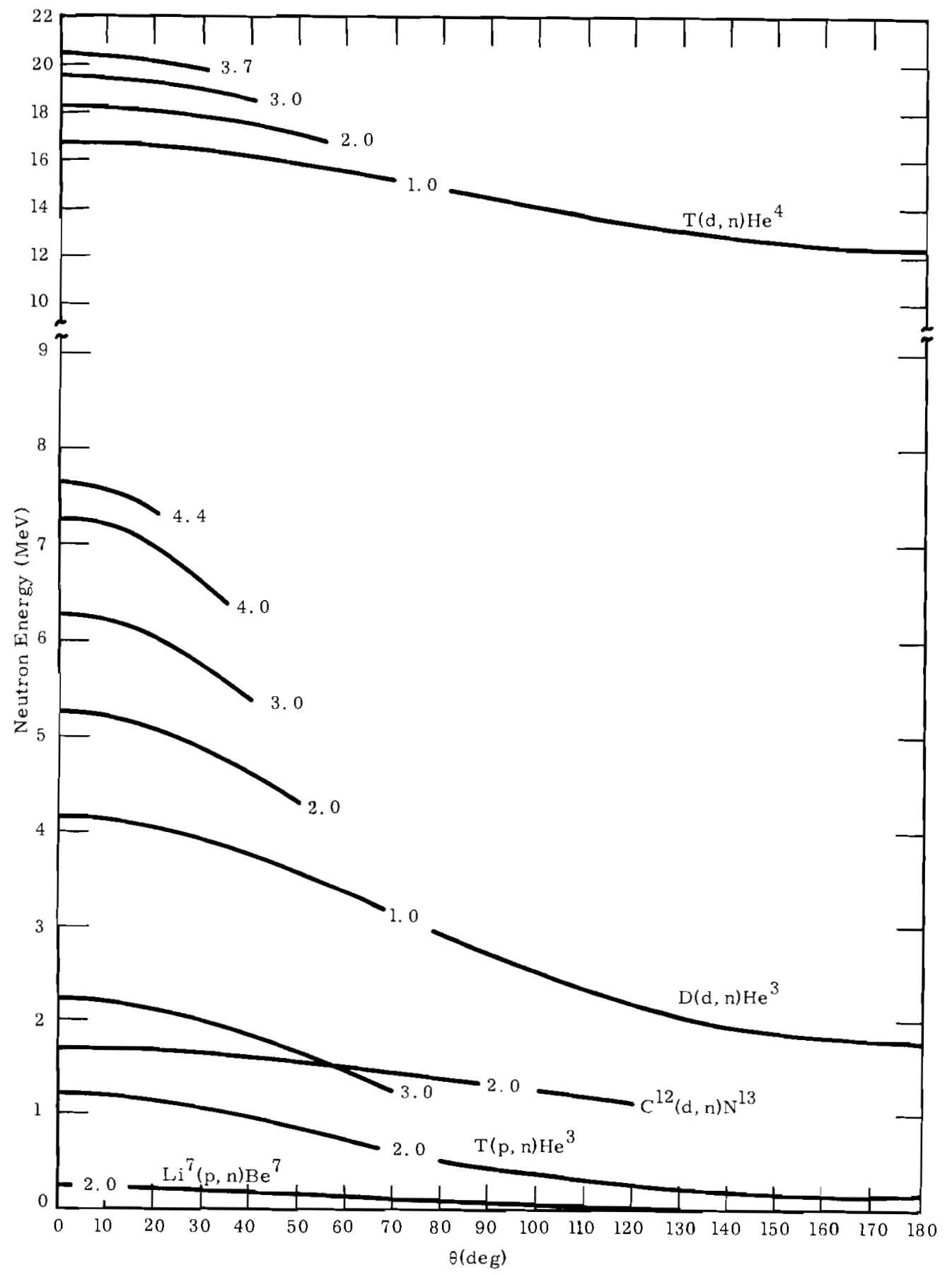

FIGURE 16. Graphs Showing How the Nuetron Energy Can Be Varied by Using a 4. $4 \mathrm{MeV}$ Accelerator at 1.0,2.0, 3.0,3.7 and 4.0 MeV Bombarding Energy 


\section{REPRODUCIBILITY CHECKS ON PLC'S}

The small extreme variation of $1.4 \%$ in the values of $\mathrm{w}(\mathrm{Y})$ for eight selected PLC's demonstrates the possibility that additional PLC's can be built to have that kind of reproducibility. However, the eight PLC's were all built for people in the U.S. A. who have been in close communication with one another during the construction of the PLC's and who have had access to the same kinds of construction materials. For example, the good reproducibility of the $\mathrm{H}-1$, NBS-1, and $\mathrm{H}-3 \mathrm{PLC}$ 's resulted from the selection of parts from a fairly large supply of spare parts during the early stages of the development of the PLC. It is clear from inquiries regarding the construction of the PLC that a number of them have been constructed or are being considered for construction. The roving counter, $\mathrm{H}-3$, is available on request* for checking on the reproducibility of a given PLC as compared to $\mathrm{H}-1$. It should be transported under controlled temperature conditions to avoid a recurrence of the sensitivity change which was demonstrated for $\mathrm{H}-3$ in Table IX.

Requests** may be made to calibrate a given internal neutron source against the PuBe standard M-1045. When the internal source is a PuBe source, complete reliance should not be placed on an isotopic analysis $^{(12)}$ to establish its rate of change of growth rate, $\beta$, but rather on direct measurements of it.

The drawings which are presently available commercially for the PLC describe a brass $\mathrm{BF}_{3}$ tube assembly which was used for most of the work described in this report. However, the superior radiation resistance of the copper walled $\mathrm{BF}_{3}$ tubes which were employed to obtain the data presented in Tables I and II and in Figure 5 lead to this tube being preferred to the brass tube. Specifications for the construction of the copper tube are given in Appendix A.

* To request a loan of PLC-H-3, please contact L. L. Nichols, BattelleNorthwest, 3745-B Building, 300 Area, Richland, Washington.

**To request a calibration of an internal neutron source against the $\mathrm{PuBe}$ standard M-1045, please contact Mr. M. E. Anderson, Monsanto Research Corporation, Mound Laboratory, Miamisburg, Ohio. 


\section{ACKNOWLEDGMENTS}

A number of people have contributed significantly to the work recorded in this report during the period of time 1958 through 1965. The work started because of the favorable response to the concept of a precision long counter from Dr. R. S. Caswell at the National Bureau of Standards and the Neutron Task Group Subcommittee M(2) of the National Committee on Radiation Protection in 1958. Dr. Caswell and Mr. A. C. B. Richardson also of the National Bureau of Standards are thanked for their interest in the PLC, for the loan of the counter NBS-1, for the loan of the neutron sources NBS-II and NBS-H, and for the loan of the first copper walled $\mathrm{BF}_{3}$ tubes which were used in the work.

The accuracy of the PLC measurements was seria sly impaired because of the lack of knowledge of the rate of changes of the neutron growth rates for the PuBe sources until Mr. M. E. Anderson, step by step, provided the required information from studies he initiated at the Mound Laboratory. Mr. Anderson is also thanked for his continuing interest in the PLC work over most of the reporting period, for the loan of the source M-590, and, especially, for the exchange of information regarding the accuracy of measurements made with PLC's on radioactive neutron sources.

Dr. L. L. Anderson at the Argonne National Laboratory is thanked for his interest in the PLC work, for his comments on the interpretation of our data on the finite-size effect of the PLC, and for providing information he obtained in comparing the sensitivity of his counter ANL-1 with the roving counter $\mathrm{H}-3$.

Dr. R. L. Bramblett at the Lawrence Radiation Laboratory in Livermore is thanked for his interest in the PLC work by loaning his counter $\mathrm{L}-1$ for direct measurements against the counter $\mathrm{H}-1$.

Mr. M. L. Leibel of the Hanford Laboratories and now of the Battelle-Northwest Laboratories is thanked for his careful work in 
making many measurements with the PLC's and in operating the Van de Graaff accelerator. Finally, Dr. W. C. Roesch of the Hanford Laboratories and now of the Battelle-Northwest Laboratories is thanked for his encouragement and interest in the work over its entire course.

\section{REFERENCES}

1. J. DePangher. "A Reproducible Precision Polyethylene Long Counter for Measuring Fast Neutron Flux," Bull. Amer. Phys. Soc., Series II, vol. 6, pp. 252. 1961.

2. A. O. Hanson and J. L. McKibben. "A Neutron Detector Having Uniform Sensitivity from $10 \mathrm{KeV}$ to $3 \mathrm{MeV}$, "Phys. Rev., vol. 72, pp. 673-677. 1947.

3. W. D. Allen and A. T. G. Ferguson. "The Measurement of Fast Neutron Flux over the Neutron Energy Range $0.03 \mathrm{MeV}$ to $3.0 \mathrm{MeV}$," Proc. Phys. Soc., vo1. A70, pp. 639-653. 1957.

4. J. E. Perry, Jr. Personal Communication. Los Alamos Scientific Laboratory, Los Alamos, New Mexico. March 1957.

5. J. DePangher. Neutron Measurements III: Calibration of Long Counter No. 2 with Radioactive Neutron Sources, HW-56199. General Electric Company, Richland, Washington. May 1958.

6. E. E. Donaldson. "Precise Positioner for Large Instruments," Nucleonics, vol. 17, no. 3, pp. 94. 1959.

7. J. DePangher, L. L. Nichols, and R. A. R. Kent. Characteristics of a Large Moderator for Activation Studies, HW-73913. General Electric Company, Richland, Washington. August 1962.

8. R. D. McCormick and J. D. McCormack. "Hydrogen and Carbon Target Preparation for a Positive Ion Accelerator, "Nucl. Inst. and Meth. , vol. 13, pp. 147-152. 1961

9. A. C. B. Richardson. "Low Scatter High Current Gas Target for D-D Neutrons, Rev. Sci. Inst., vol. 31, pp. 1202-1203. 1960.

10. O. J. C. Runnals and R. R. Boucher. "Neutron Yields from ActinideBeryllium Alloys," Can. J. Phys., vol. 34, pp. 949-958. 1956.

11. National Bureau of Standards Handbook No. 72. U. S. Government Printing Office, Washington, D. C., p. 9.1960.

12. M. E. Anderson. "Increase in the Neutron Emission Rates of Plutonium Beryllium Sources," Trans. Amer. Nuc. Soc., vol. 7, no. 2, pp. 246-247. 1964.

13. M. E. Anderson and R. L. Bramblett. Personal Communications. Monsanto Research Corp. , Miamisburg, Ohio and Lawrence Radiation Laboratory, P. O. Box 808, Livermore, California. December 2 and 22,1964 . 
14. K. W. Geiger. Personal Communication. National Research Council, Ontario, Canada. June 15, 1961.

15. M. E. Anderson. Use of a Long Counter for the Routine Comparison of Total Emission Rates of Radioactive Neutron Sources. Mound Laboratory, Miamisburg, Ohio. February 1964.

16. J. B. Scarborough. Numerical Mathematical Analysis, Fifth Edition. The John Hopkins Press, Baltimore, Md., pp. 150-159. 1962 .

17. J. DePangher, "Double Moderator Neutron Dosimeter, Nucl. Inst. and Meth., vol. 5, pp. 61-74。 1959. Also: J. DePangher. "Table 2," Nucl. Inst. and Meth., vol. 21, p. 360. 1963.

18. R. H. Moore and R. K. Zeigler. The Solution of the General Least Square Problem with Special Reference to High Speed Computers, LA-2367. Los Alamos Scientific Laboratories, Los Alamos, New Mexico. March 1960.

19. J. DePangher. "Energy Spectra for Several Radioactive Neutron Sources, "Bull. Amer. Phys. Soc., Series II, vol. 8, p. 370. 1960.

20. J. E. Brolley, Jr. and J. L. Fowler. "Monoenergetic Neutron Sources with Light Nuclei," Fast Neutron Physics, Part II. Interscience Publishers, Inc., New York, N. Y., pp. 80-81. 1960.

21. M. E. Anderson. Personal Communication. Mound Lāboratory, Miamisburg, Ohio. May 1962.

22. L. BIumberg and S. I. Schlesinger. Relativistic Tables of Energy and Angle Relationships for the $T(p, n) \mathrm{He}^{3}, D(d, n) \mathrm{He}^{3}$, and $\mathrm{T}(\mathrm{d}, \mathrm{n}) \mathrm{He}^{3}$ Reactions, AECU-3118. Los Alamos Scientific Laboratory, Los Alamos, New Mexico. May 1956.

23. H. H. Barshall. "Neutron Experiments with A Tandem Accelerator," Nucl. Inst. and Meth., vol. 28, pp.44-51. 1964. 


\section{APPENDIX A \\ SPECIFICATIONS FOR A COPPER WALLED BF 3 TUBE}

The following specifications have been used to obtain $\mathrm{BF}_{3}$ tubes having unusual count-rate stability characteristics. It is thought that the oxygen-free copper walls are responsible for part of these good characteristics but vendor design of other items may be heavily contributing factors.

(1) The $\mathrm{BF}_{3}$ tube is a proportional counter tube, assembly 1, high (low) sensitivity, as in drawing $\mathrm{H}-4-39122$, Rev. 4 except as follows:

a. The outside diameters to be 1.492 to $1.494 \mathrm{in}$. and the tube is to be straight to within \pm 0.002 in.

b. The resolution on the main peak in the pulse height distribution is to be $15 \%$ or less.

c. The sensitive volume is to be fixed in the sense that during the first $8 \mathrm{hr}$ after the application of the high voltage and the neutron radiation the count rate shall change by no more than $0.3 \%$.

d. Oxygen-free copper is to be substituted for the brass called out on the drawing.

e. The vendor may make changes at his discretion in the following:

i. feed-through seals and leads on ends, ii. soldering techniques,

iii. material and size of the center wire, and iv. wall thickness.

(2) One set of pulse height distribution data is required to demonstrate the achievement of the desired $15 \%$ resolution. 


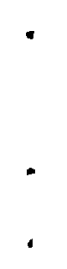




\section{APPENDIX B \\ CORRECTIONS TO THE DRAWINGS ON THE PLC}

The following corrections are to be noted in the construction drawings for the PLC as supplied by the Cooper-Trent Blueprint and Microfilm Corporation:

(1) A coarser finish than specified by the drawings is adequate for the thermal neutron shield made out of boron loaded polyethylene.

(2) The aluminum alloy, 31ST, is just as good as the $2 \mathrm{~S}$ aluminum for reproducible neutron transmission characteristics and a stronger and more durable material.

(3) The length of the source-holder rod from the center of the pin at one end to the other end of the rod is $14-1 / 2$ in., not 14 in. 


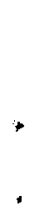

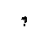

, 


\section{DISTRIBUTION}

Number of Copies

1 Argonne National Laboratory

L. D. Marinelli

1 Brookhaven National Laboratory

F. P. Cowan

1 Columbia University

H. H. Rossi

382 Division of Technical Information Extension

1 International Atomic Energy Agency

R. Dudley

$1 \quad$ Massachusetts Institute of Technology

R. D. Evans

1 National Bureau of Standards

R. S. Caswell

2 Oak Ridge National Laboratory

K. Z. Morgan

J. A. Auxier

2 Richland Operations Office

R. K. Sharp

Technical Information Library

1 Stanford University

R. C. McCall

1 University of Washington

P. Wootton

2 U. S. Atomic Energy Commission

N. F. Barr

R. W. Wood 
Number of Copies

1 U. S. Naval Radiological Defense Laboratory

E. Tochilin

$1 \quad$ U. S. Naval Research Laboratory

F. H. Attix

123

Battelle-Northwest

L. A. Braby

P. E. Bramson

E. D. Clayton

G. M. Dalen

F. G. Dawson

G. W. R. Endres

D. M. Fleming

W. A. Glass

A. R. Keene

H. A. Kornberg

B. R. Leonard

C. E. Newton

L. L. Nichols (100)

J. M. Nielson

R. S. Paul

D. N. Samsky

W. G. Spear

W. E. Wilson

Technical Information Files (5)

Technical Publications (1) 